\title{
Adipocytokines in Atherothrombosis: Focus on Platelets and Vascular Smooth Muscle Cells
}

\author{
Giovanni Anfossi, Isabella Russo, Gabriella Doronzo, Alice Pomero, and Mariella Trovati \\ Department of Clinical and Biological Sciences, Internal Medicine and Metabolic Disease Unit, \\ San Luigi Gonzaga Hospital, San Luigi Gonzaga Faculty of Medicine of the Turin University, Orbassano,10043 Turin, Italy
}

Correspondence should be addressed to Mariella Trovati, mariella.trovati@unito.it

Received 9 November 2009; Revised 14 March 2010; Accepted 29 April 2010

Academic Editor: Gema Frühbeck

Copyright ( 92010 Giovanni Anfossi et al. This is an open access article distributed under the Creative Commons Attribution License, which permits unrestricted use, distribution, and reproduction in any medium, provided the original work is properly cited.

\begin{abstract}
Visceral obesity is a relevant pathological condition closely associated with high risk of atherosclerotic vascular disease including myocardial infarction and stroke. The increased vascular risk is related also to peculiar dysfunction in the endocrine activity of adipose tissue responsible of vascular impairment (including endothelial dysfunction), prothrombotic tendency, and low-grade chronic inflammation. In particular, increased synthesis and release of different cytokines, including interleukins and tumor necrosis factor- $\alpha$ (TNF- $\alpha$ ), and adipokines - such as leptin-have been reported as associated with future cardiovascular events. Since vascular cell dysfunction plays a major role in the atherothrombotic complications in central obesity, this paper aims at focusing, in particular, on the relationship between platelets and vascular smooth muscle cells, and the impaired secretory pattern of adipose tissue.
\end{abstract}

\section{Introduction}

Subjects affected by central obesity (i.e., by intra-abdominal fat excess) are characterized by insulin resistance, metabolic disorders, and vascular abnormalities which cooperate to induce high cardiovascular risk [1-3].

The so-called "metabolic syndrome", defined on the basis of a combination of central obesity, glucose intolerance, atherogenic dyslipidemia, and arterial hypertension $[3,4]$, is present in the large majority of these subjects.

In central obesity, abnormalities in the extent and distribution of fat mass are associated with a peculiar dysfunction of adipose tissue, responsible-together with the insulin resistance-of alterations of vascular function (including endothelial dysfunction), pro-thrombotic tendency, lowgrade chronic inflammation, and oxidative stress: these defects, frequently associated as a cluster, represent the main pathogenetic link between obesity and the increased risk of athero-thrombotic events [5-7].

Omental adipose tissue, which comprises both adipocytes and a stromovascular cell fraction, is not an inert lipid storage site, but a dynamic endocrine organ able to synthesize and secrete many bioactive peptidescollectively named "adipocytokines"-deeply involved in the metabolic, vascular, and immunological homeostasis by paracrine and endocrine mechanisms $[2,6,8-10]$.

Some molecules, directly synthesized by adipocytes and called "adipokines" (i) control energy balance and appetite, and influence insulin sensitivity via endocrine mechanisms, and (ii) modulate adipocyte size/number and angiogenesis via paracrine mechanisms, thus exerting a major role in the regulation of fat mass $[10,11]$. Furthermore, they can also exert a role in the control of blood pressure, lipoprotein metabolism, coagulation, immunity and inflammation [5, $11]$.

Other peptides belonging to the cytokine groupproduced and released by the stromal vascular components of adipose tissue (i.e., lymphocytes, fibroblasts, macrophages, endothelial cells, and preadipocytes) $[8,9,12-$ 14] - are mainly involved in local and systemic inflammation $[8,13-16]$. The increase in abdominal adipose tissue mass dysregulates both adipokine and adipocytokine secretion patterns $[10,14]$. 
With the exception of the insulin sensitizing peptide adiponectin, adipokine production and secretion are increased in central obesity $[10,11,15]$ : this fact plays a pivotal role both in the pathogenesis of cardiovascular damage through adverse effects on hemostatic balance and vascular function $[5,6,11]$, and in the amplification of inflammatory processes in vascular and nonvascular tissues $[11,13,15]$.

Also, cytokine release is enhanced: this phenomenon is attributable to increased prevalence of hypertrophied adipocytes with altered adipokine synthesis and secretion, local hypoxia, as well as activation of resident inflammatory cells and macrophages [14, 15].

In particular, adipose tissue from individuals with central obesity synthesizes and releases increased amount of

(i) proinflammatory chemokines and cytokines, such as Monocyte Chemoattractant Protein-1 (MCP1), macrophage migration inhibitory factor (MIF), tumor necrosis factor- $\alpha$ (TNF- $\alpha$ ), and interleukins, including interleukin-1 $\beta$ (IL-1 $\beta$ ) and interleukin-6 (IL-6) [15];

(ii) procoagulant and proinflammatory mediators such as tissue factor (TF) and plasminogen activator inhibitor-1 (PAI-1) [15];

(iii) vasoactive substances such as angiotensinogen and endothelin-1 (ET-1) [17, 18];

(iv) molecules involved in the pathogenesis of insulin resistance, such as TNF- $\alpha$ and resistin $[8,10,13-16]$.

Since central obesity is characterized by an enhanced cardiovascular risk, and it is known that dysfunctions of platelets and vascular smooth muscle cells (VSMC) are deeply involved in athero-thrombosis [19-22], the purpose of this review is to identify the actions of adipokines and adipocytokines on these cells, focusing in particular on the role of inflammation.

\section{Role of Platelets in Thrombosis and Inflammation}

Platelets are anuclear cell fragments released from megakaryocytes, hematopoietic cells that differentiate and undergo endomitosis $[23,24]$. Despite the lack of nucleus, they contain mRNA and spliceosomal components for mRNA processing, as well as the translational machinery for protein synthesis $[23,25]$ : this justifies de novo synthesis by platelets of different mediators involved in the regulation of inflammatory and coagulant pathways including IL- $1 \beta$, PAI- 1 , and TF $[26,27]$.

As evidenced in Figure 1, platelets play a pivotal role in the response to vascular injury through adhesion to exposed subendothelial layer triggered by different collagen types and adhesive proteins such as von Willebrand factor (vWF), fibronectin, laminin, fibulin and thrombospondin [26-29]. Activation of platelets by components of the subendothelial matrix is linked to exposure of membrane glycoprotein receptors including GPIb/V/IX complex which interacts with
vWF, integrin $\alpha \operatorname{IIb} \beta_{3}$ (GPIIb/IIIa) able to bind Arg-Gly-Asp [RDG] domain of vWF and fibrinogen, and GPVI which ensures a stable anchorage with subendothelial matrix by direct interaction with collagen [26-30]. Platelet activation and formation of aggregates are triggered also by thrombin [31], endogenous mediators released from storage granules and erythrocytes such as adenosine 5-diphosphate (ADP), and de novo synthesis of platelet activating factor (PAF), and thromboxane $\mathrm{A}_{2}\left(\mathrm{TXA}_{2}\right)$ [30, 32-34].

As shown in Figure 2, activated platelets also release inflammatory mediators from granules, including plateletderived growth factor (PDGF) and platelet factor 4 (PF-4) [35-37].

Beyond acute activation as a consequence of vascular injury, circulating platelets are actively involved in all phases of the atherogenetic process, from atherosclerotic plaque formation to plaque inflammation and rupture [28, 37-39]. In these conditions, platelet reactivity is increased by reactive oxygen species (ROS) produced as a consequence of oxidative stress, by reduction of endothelial antithrombotic properties and by the increased availability of proinflammatory mediators, such as cytokines and chemokines [40, 41].

Actually, platelets release several mediators linking thrombosis and vascular inflammation such as the RANTES (regulated on activation, normal T-cell expressed and secreted) chemokine, PDGF, PF-4, Transforming growth factor- $\beta$ (TGF- $\beta$ ), CD40 ligand (CD40L, CD154), P-selectin, and $\mathrm{TXA}_{2}[35-37,41]$.

RANTES recruits monocytes and $\mathrm{T}$ cells; in conjunction with P-selectin this chemokine can be immobilized on inflammed endothelial cells, thus inducing monocyte arrest and migration [41].

PDGF, the major growth factor contained in platelets [36-38], stimulates both migration and proliferation of VSMC by co-operation with serotonin, and TGF- $\beta[36,42$, $43]$, and is chemotactic for monocytes [38, 43]; its effects on VSMC are critical for the development of atherosclerotic process [27, 37, 38].

PF-4-a member of the C-X-C chemokine subfamilyexerts chemotactic effects on monocytes, promotes monocyte-to-foam cell differentiation $[27,35,36]$, enhances the binding of oxidized low density lipoproteins (LDL) to vascular wall, and inhibits LDL degradation through the LDL receptors $[35,44]$.

CD40L is a trimeric protein structurally related to TNF$\alpha$ superfamily stored in the $\alpha$-granules of resting platelets [45-49]. After platelet activation, it is rapidly exposed on cell surface and cleaved to release the soluble fragment (sCD40L) able to increase the stability of new platelet aggregates [49], and to activate vascular inflammatory mechanisms by inducing production of ROS, enhancing expression of adhesion molecules Vascular Cell Adhesion Molecule-1 (VCAM-1), Intercellular Adhesion Molecule-1 (ICAM-1), and E-selectin in endothelial cells and VSMC, and increasing secretion of cytokines, chemokines, matrix metalloproteinases (MMPs), and procoagulant factors [45-48].

Several cell types-including endothelial cells, VSMC, monocytes, neutrophils, B cells and fibroblasts-bind CD40L through the specific receptor CD40 $[45,50]$. This 


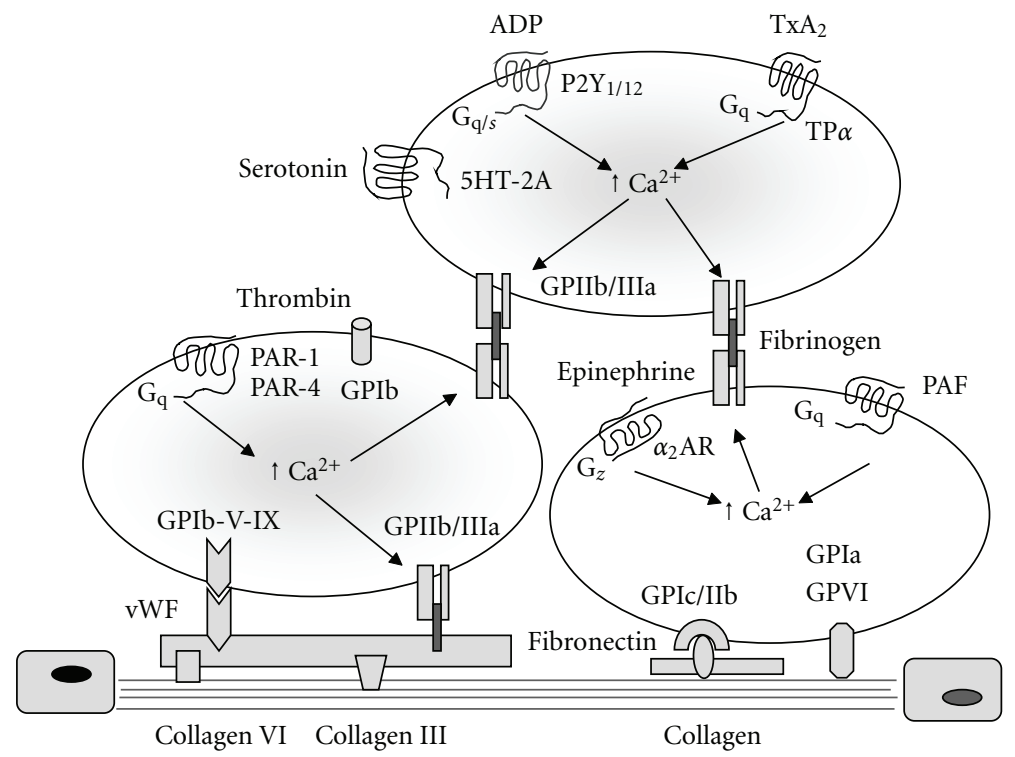

FIGURE 1: Mechanisms involved in platelet adhesion to subendothelial layer and activation. The diagram illustrates the role of von Willebrand factor (vWF), collagen and other proteins in platelet adhesion by linking to exposure of membrane glycoprotein receptors including GPIb//V/IX complex, GPIIb/IIIa, and GPVI which ensures a stable anchorage with subendothelial matrix by interaction with collagen. Platelet activation and aggregation are triggered by thrombin, endogenous mediators released from storage granules, and synthesis of platelet activating factor (PAF), and thromboxane $\mathrm{A}_{2}\left(\mathrm{TXA}_{2}\right)$. P2Y1/12, purinergic P2Y receptors; TP $\alpha$, thromboxane $\alpha$ receptor; 5HT-2A, serotonin (5-hydroxytryptamine)-2A receptor; PAR-1, protease-activated receptor-1; PAR-4, protease-activated receptor-4; $\alpha_{2}$ AR, $\alpha_{2}$ adrenoreceptor.

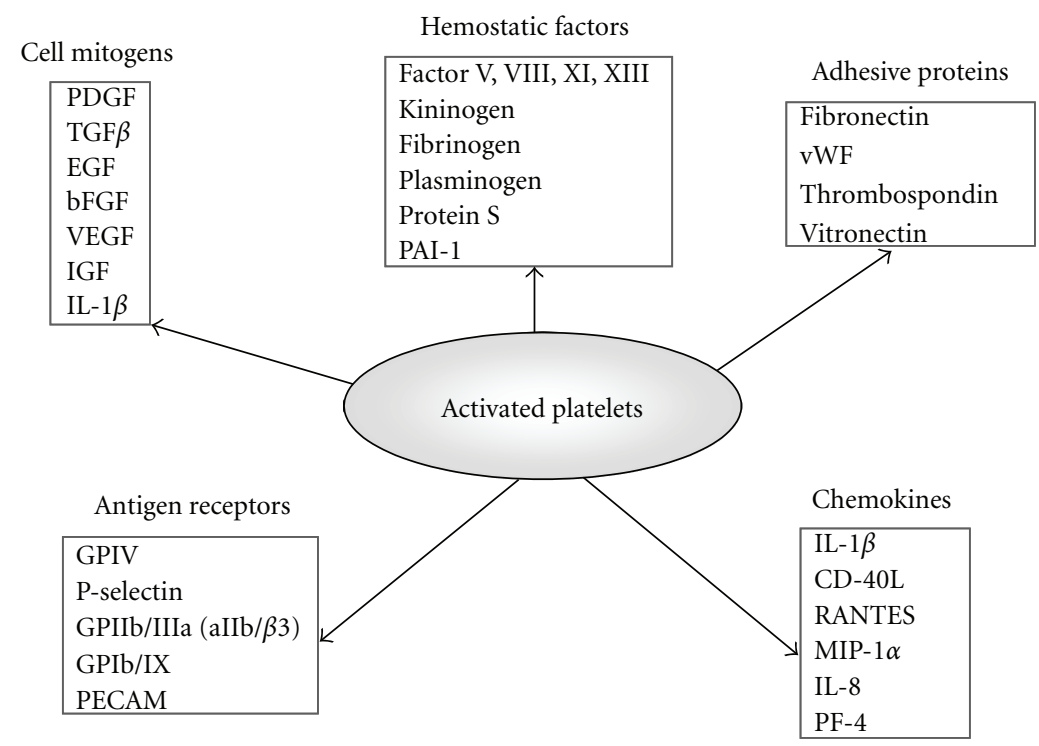

FIGURe 2: Platelet components involved in the coagulation cascade and the atherosclerotic process. PDGF, platelet-derived growth factor; TGF $\beta$, transforming growth factor $\beta$; EGF, endothelial growth factor; bFGF, fibroblast growth factor; VEGF, vascular endothelial growth factor; IGF, insulin-like growth factor; IL-1 $\beta$, interleukin-1 $\beta$; PAI-1, plasminogen activator inhibitor 1; vWF, von Willebrand factor; GP, glycoproteins; PECAM, platelet and endothelial cell adhesion molecule; CD40L, CD40 ligand (CD154); RANTES, regulated on activation, normal T-cell expressed and secreted; MIP- $1 \alpha$, macrophage inflammation protein $1 \alpha$; IL-8, interleukin-8; PF4, platelet factor 4.

receptor has been recently identified also in adipocytes where it plays a relevant role in the crosstalk with resident lymphocytes [51]; furthermore, circulating sCD40L levels have been found at abnormally high levels in patients with obesity, type 2 diabetes mellitus and atherosclerotic vascular diseases [52-55].
P-selectin is stored in platelet $\alpha$-granules [36] and, after activation, rapidly translocated upon cell surface becoming accessible to circulation; this phenomenon strengthens initial rolling contact between platelets and vessel wall and promotes RANTES deposition on endothelial cells, thus increasing monocyte recruitment [27-29, 41, 47, 56]. 

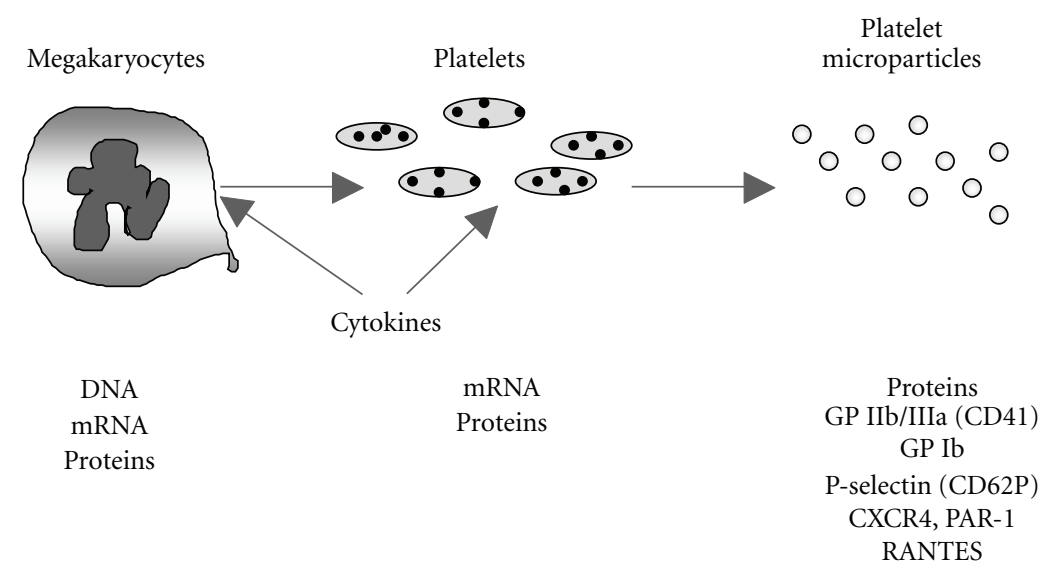

FIGURE 3: General features of circulating platelet microparticles (PMPs). PMPs are phospholipid microvesicles of 0.1-1 micron in size, sheded from parental cell fragments after stimulation with physiological agonists such as thrombin or collagen or exposure to shear stress (i.e., in severe stenosis). PMPs express functional adhesion receptors, including GPIIb/IIIa (CD41), P-selectin (CD62P), CXCR4, and PAR-1 and contain different proteins and coagulation factors, thus exerting a role in the hemostatic response and in the interplay between coagulation and inflammation. PMPs also simulate cytokine release and adhesion molecule expression in endothelial cells and contraction of VSMC. Elevated levels of circulating PMPs have been described in patients with arteriosclerosis, acute vascular syndromes, diabetes mellitus, as well as central obesity. GPIIb/IIIa, glycoprotein IIb/IIIa; GP Ib, glycoprotein Ib; CXCR4, chemokine (C-X-C motif) receptor 4; PAR-1, proteaseactivated receptor-1; RANTES, regulated on activation, normal T-cell expressed and secreted.

Platelet stimulation by agonists or exposure to high shear stress leads to formation and release of platelet-derived membrane-coated vesicles termed platelet microparticles (PMPs) [57, 58], which influence the activities of other cell types both regionally and systemically [58]. As evidenced in Figure 3, PMPs are lipid-protein complexes with a diameter $<1 \mu \mathrm{m}$, composed by vesicular fragments of the plasma membrane and $\alpha$-granules [59]: their protein content plays a relevant role in both hemostasis and inflammation, by facilitating coagulation, promoting platelet and leukocyte adhesion to the subendothelial matrix, supporting angiogenesis and stimulating VSMC [58-60]. These effects may contribute to the chronic inflammatory state which characterizes atherosclerosis [58]; in particular, a portion of platelet-derived IL- $1 \beta$ associated with PMPs stimulates the production of chemoattractant molecules and cytokines and the expression of specific adhesion molecules in endothelial cells, thus enhancing their interaction with circulating leukocytes and, therefore, their ability to trigger inflammatory responses [61, 62]. Also the chemokine RANTES is delivered to sites of endothelial injury via PMPs to promote monocyte recruitment $[56,63]$.

\section{Alterations of the Platelet Function in Central Obesity}

Platelet hyperactivity is deeply involved in the increased atherothrombotic risk of patients affected by central obesity and type 2 diabetes mellitus [20, 21, 64].

A variety of defects of platelet function-mainly related to increased adhesiveness and activability in vivo and reduced sensitivity to physiological antagonists - has been identified in central obesity, as recently reviewed [20, 21].
Mean volume of circulating platelets-a parameter directly related to in vivo platelet activation [65] relevant to predict myocardial infarction occurrence and mortality and restenosis following coronary angioplasty [66] — is increased in obese patients, independently of the presence of other cardiovascular risk factors $[66,67]$; furthermore, a positive correlation between body mass index (BMI) and mean platelet volume (MPV) has been found in obese individuals [66-69], whereas weight loss may lead to a decrease in platelet size and reactivity [68].

Increasing evidences indicate that the size of circulating platelets deeply influences their hemostatic potential being the response of larger platelets to aggregating stimuli more rapid and the amount of released mediators increased $[65,70]$.

Platelet volume, as well as other platelet parameters, are mainly determinated during megakaryocyte fragmentation in bone marrow [71, 72]. Even though the mechanisms influencing magakaryocytopoiesis are not completely understood, an involvement of inflammatory cytokines (including interleukins $-1,-3,-6,-8,-11$, and -18$)$, and of nitric oxide (NO) has been shown in some studies [73, 74]; this phenomenon allowed to hypothesize that the increased production and release of proinflammatory cytokines, as well as endothelial dysfunction of central obesity, might influence megakaryocytopoiesis and circulating platelet volume [75].

The increased in vivo activation of circulating platelets is mirrored by the enhanced expression of activationdependent adhesion molecules, and by increased plasma concentrations of sP-selectin; another index of in vivo platelet activation-that is, urinary excretion of 11 -dehydro- $\mathrm{TXB}_{2}$, the major enzymatic metabolite of $\mathrm{TXA}_{2}$ - is increased in women affected by visceral obesity, compared to non-obese women [76]. 
Relevant defects of platelet function in central obesity are related also to a reduced sensitivity to mediators-such as insulin, prostacyclin $\left(\mathrm{PGI}_{2}\right)$, and $\mathrm{NO}$ - which in lean subjects reduce platelet sensitivity to proaggregating stimuli [21].

Insulin, which physiologically reduces platelet responses to agonists both in vitro [77-79] and in vivo [77, 80, 81], mainly through a NO-dependent mechanism mediated by the increase of intraplatelet cyclic nucleotides $3^{\prime}, 5^{\prime}$ cyclic guanosine monophosphate (cGMP) and $3^{\prime}, 5^{\prime}$-cyclic adenosine monophosphate (cAMP) [78, 82], exhibits a deeply impaired antiaggregating effect in insulin resistant states, such as central obesity, type 2 diabetes mellitus with obesity and essential arterial hypertension $[81,83-85]$.

Furthermore, platelets from obese subjects or obese type 2 diabetic patients show defective responses to the $\mathrm{NO} /$ cyclic nucleotide/protein kinase pathway including the ability of $\mathrm{NO}$ and NO donors to increase cGMP, the ability of cGMP to reduce platelet calcium and consequently aggregation $[86,87]$; similarly, also the ability of $\mathrm{PGI}_{2}$ to increase cAMP and of cAMP to reduce platelet function are impaired in these patients [87].

As previously mentioned, a relevant factor causing plaletet dysfunction is the increased oxidative stress [40], which is present in central obesity, as a consequence of imbalance between ROS production and reduced levels of substances able to protect from the damage of free radicals and peroxides [88]. Several metabolic abnormalities of the patients with visceral obesity-that is, excess of circulating free fatty acids, of oxidized LDL, and of proinflammatory adipokines and cytokines-contribute to ROS production $[88,89]$.

Some adipokines and inflammatory cytokines such as TNF- $\alpha$ and leptin are involved in enhanced oxidative stress $[88,89]$; furthermore, the increase in fat mass, as well as the pathological secretion pattern of adipocytes decrease the availability of antiinflammatory proteins such as adiponectin and ghrelin, which exert also protective effects against oxidative stress $[15,90,91]$.

High concentrations of ROS influence platelet function by different mechanisms, including decreased NO bioavailability, calcium mobilization abnormalities and overexpression of membrane glycoproteins [40, 92-94].

Isoprostanes are a family of prostaglandin-like metabolites produced in vivo from esterified arachidonic acid of cell membrane phospholipids or lipoproteins [95, 96] through a ROS-dependent mechanism [96-99], completely independent of cyclo-oxygenase-1 (COX-1) activity [95-97]. Once released, they circulate in plasma and are available for receptorial interaction with platelets and cells of the vascular wall; in particular, 8-iso-prostaglandin- $F_{2 \alpha}$ (8-iso- $\left.P G F_{2 \alpha}\right)$, which is an abundant isoprostane compound formed in vivo in humans, induces vasoconstriction and amplifies the adhesive reactions and the aggregating responses of human platelets to agonists $[100,101]$.

Several studies showed a stimulatory interaction of isoprostanes with $\mathrm{TXA}_{2}$ receptors $[102,103]$, which is prevented by $\mathrm{TXA}_{2}$ receptor antagonism but not by COX-1 inhibition [99]. Recently, a further isoprostane binding site, responsible of cAMP reduction, has been recognized [103].
The increased levels of F2-isoprostanes observed in visceral obesity [104-107] can be involved both in the persistent platelet activation in vivo [104], and in the resistance to antiplatelet effects of aspirin [21].

\section{Alterations of the Vascular Smooth Muscle Cells in Obesity}

4.1. Role of Vascular Smooth Muscle Cells in Physiological Conditions. In physiological conditions VSMC play an essential role in providing structural integrity of the vessel wall and in controlling vascular tone and blood pressure $[108,109]$; in particular, this cell type is the main target of the effects of endothelium-released NO, which stimulates the synthesis of cGMP, thus preventing the calcium release from intracellular stores $[110,111]$. The inhibition of calciumdependent Rho/Rho kinase pathway is a relevant mechanism involved in the modulation of VSMC relaxation induced by the NO/cGMP/PKG pathway [112].

The surface complex system which regulates VSMC responses and modulates the contractile process involves the expression of receptors for catecholamines, acetylcholine, serotonin, histamine, purinergic mediators, angiotensin II (Ang II), bradykinin, neuropeptide Y, Vasoactive Intestinal Polypeptide (VIP), vasopressin, oxytocin, prostanoids, leukotrienes, and growth factors [PDGF, Epidermal Growth Factor (EGF), TGF- $\beta$, Fibroblast Growth Factor (FGF), insulin, and Insulin-like Growth Factor (IGF-1)] [113, 114]. The signal transduction system following membrane activation is played by guanine nucleotide regulatory proteins, phosphoinositide metabolism, cyclic nucleotides (cAMP and cGMP), and calcium $[113,114]$.

Different agonists modulate VSMC responses by activating tyrosine kinases through receptor and nonreceptor mechanisms. In particular, IGF-1 through its specific receptor leads to direct activation of extracellular signal regulated kinases (ERK 1/2), whereas Ang II and other mediators activate tyrosine kinase pathway by indirect mechanisms such as increased hydrogen peroxyde $\left(\mathrm{H}_{2} \mathrm{O}_{2}\right)$ production mediated by NADPH oxidase $[113,114]$.

Furthermore, VSMC which exhibit functional insulin receptors able to activate the classical signaling pathwaysthat is, Insulin Receptor Substrates/phosphatidylinositol 3kinase (IRS/PI3-K) pathway and Mitogen-Activated Protein Kinase (MAPK) pathway [115-118], are targets of insulin action [115]. Through the PI3-K pathway, insulin stimulates glucose transport, induces the well-differentiated contractile state, antagonizes the effects of PDGF and increases NO production through NO synthase (NOS) activation $[22,78$, $115,116]$; in the presence of PI3-K inhibitors, insulin, via the MAPK pathway, influences chemotaxis [117], DNA synthesis and proliferation [118-120].

In our previous studies in cultured human and rat arterial VSMC, we observed that insulin, through NOS activation with PI3-K-dependent mechanism, elicits a concentrationdependent increase of cGMP levels, increases cAMP content, and enhances the effects of the $\mathrm{PGI}_{2}$ analogue Iloprost, of $\beta$-adrenoceptor agonists and of forskolin on cAMP levels 
$[22,78,84]$. Insulin attenuates also the agonist-induced increase of intracellular calcium by inhibiting the inositoltriphosphate sensitive calcium release from intracellular stores and by some other biochemical mechanisms mediated by the PI3-K pathway $[22,78,84,115]$.

Furthermore, insulin can influence the hemodynamic balance also through the synthesis and secretion of vasoconstrictive agents such as ET-1 [22, 78, 84, 115].

Finally, via the cooperation of the two pathways, insulin activates the Hypoxia Inducible Factor (HIF)/Vascular Endothelial Growth Factor (VEGF) pathway [22, 78, 121, 122]. HIF-1 represents a "master switch" protein generated in response to hypoxia, able to influence erythropoiesis, vasomotion, glucose metabolism, cell proliferation and survival, iron metabolism and angiogenesis; in normoxic conditions, the HIF-1 system is also induced by cytokines and growth factors $[123,124]$. VEGF is a mitogen and a survival factor for endothelial cells, able to induce vascular permeability and to regulate physiological and pathological angiogenesis, with a particular role in the postischemic revascularization [125].

\subsection{Vascular Smooth Muscle Cells in the Pathogenesis of} Atherosclerosis. Following repeated or chronic arterial wall injury, such as in arterial hypertension and exposure to other cardiovascular risk factors, VSMC respond by migration into the intima, secretion, as well as by increased proliferation [38, 126, 127].

VSMC migration to the intima from the media depends on mechanisms regulated by soluble growth factors/chemoattractants, as well as by interactions with extracellular matrix $[38,126,127]$. The secretion process increases extracellular matrix formation as well as the release of proteins involved both in the digestion of major components of the extracellular matrix, such as MMPs [128-130], and in angiogenesis, such as HIF-1 and VEGF [131-134].

A stimulating role on VSMC is exerted by cytokines and growth factors, including IL- $1 \beta$, IL-6, TGF- $\beta 1$, TNF- $\alpha$, thrombin, bFGF, IGF-1, PDGF, urokinase plasminogen activator (u-PA), Ang II, and VEGF [38, 126, 127, 133-137]; cytokine-dependent activation, in particular, increases the synthesis of MMPs and their processing from inactive zymogens to the active enzymes [128-130, 138-141]; the same effect has been recently described for C-reactive protein (CRP) [140], and for sCD40L, which increases VSMC proliferation and migration through the MMP-9 pathway [47, 142].

Enhanced proliferation of VSMC has been considered for many years only a mechanism involved in atherosclerotic plaque formation; however, since plaques prone to rupture (the so called "unstable" plaques) show a paucity of VSMC compared with the "stable" ones [143], it has been recently recognized a beneficial role of VSMC also in plaque stabilization and therefore in one of the main mechanisms involved in the prevention of cardiovascular events which are the consequence of plaque rupture and superimposed thrombosis [144]. In recent years, the role of VSMC apoptosis within the atherosclerotic plaques [145, $146]$, has been considered one of the major causes of plaque rupture by thinning the fibrous cap [147, 148]. Furthermore, VSMC apoptosis has proinflammatory effects and increases macrophage infiltration through the release of IL- $1 \alpha$ and the up-regulation of MCP-1 and interleukin-8 (IL-8), responsible of macrophage infiltration in vivo [146, 148, 149]; in vitro studies showed that VSMC apoptosis also promotes both thrombin generation [150], and vascular calcification [151].

Finally, through the generation and release of microparticles, apoptotic vascular cells are thrombogenic locally, thus contributing to increase the thrombogenic potential of the lipid core [152], and systemically [153]; evidences from in vitro studies support this effects by showing that microparticles containing TF are released by cultured VSMC in response to stimuli mimicking minimal apoptosis or flow conditions [154].

Migration and proliferation of VSMC are also under the inhibitory control of the nuclear receptors Peroxisome Proliferator-activated Receptor (PPAR) alpha $[155,156]$ and gamma [157].

4.3. Impairment of Vascular Smooth Muscle Cells in Insulin Resistance States and Obesity. In obese subjects several studies showed an impaired arterial vasodilation, mainly involving cerebral, mesenteric, coronary, and skeletal muscle districts [158, 159]; a pivotal role in this phenomenon is played by endothelial dysfunction related to increased secretion of proinflammatory cytokines, reduced circulating levels of adiponectin, and enhanced release of free fatty acids: all these abnormalities alter gene expression and cell signaling in vascular endothelium, cause vascular insulin resistance, modify the release of endothelium-derived factors, and increase vascular oxidative stress [158-163]. In particular, the altered pattern of adipocytokine secretion characterizing central obesity-that is, reduced adiponectin and elevated levels of leptin, resistin, $\mathrm{TNF} \alpha$, and IL-6-increases the production of superoxide anion $\left(\mathrm{O}_{2}{ }^{-}\right)$, that interferes with NO availability, thus reducing vasodilation $[163,164]$.

Furthermore, insulin resistance, which characterizes human obesity and involves also the vascular effects of the hormone $[115,123,165,166]$, can determine per se hemodynamic consequences by impairing the balance between the vasodilating insulin actions exterted via the $\mathrm{NO} / \mathrm{cGMP} / \mathrm{PKG}$ pathway and the vasoconstricting-ones mainly exerted via ET-1 in favour of the last-ones, as extensively reviewed $[22,78,84,115,123,167]$.

Since VSMC from animal models of insulin resistance show alterations in mechanisms involved in vasodilation, migration, and proliferation, a role of these vascular cells in hemodynamic alterations of obesity cannot be ruled out [22].

As previously mentioned NO/cGMP/PKG pathway plays a key role in VSMC-dependent vascular responses in physiological states $[110,111]$ : in particular, PKG initiates several phosphorylation events leading to VSMC relaxation through a reduction of free intracellular calcium levels, a decreased sensitivity of the contractile apparatus to calcium, a rearrangement of cytoskeleton, a dephosphorylation of myosin light chain, and a phosphorylation of two filament-actin 
binding proteins, Vasodilatory-Stimulated Phosphoprotein (VASP) and the $20-\mathrm{kDa}$ heat shock-related protein (HSP20) [111]. PKG is also involved in VSMC proliferation and differentiation via its ability to modulate gene expression and protein synthesis [111].

Studies from our laboratory showed that VSMC from obese, insulin-resistant Zucker fa/fa rats-the classical animal model of insulin resistance due to defects in leptin receptors-show a reduced insulin ability to increase NO synthesis [121], and a reduced response to the NO/cGMP/PKG pathway [168]. In particular, VSMC from obese Zucker fa/fa rats shows: (i) baseline higher cGMP concentrations due to a reduced catabolism by phosphodiesterases; (ii) impairment of the NO ability to increase cGMP by activating the soluble guanylate cyclase; (iii) reduction of the NO and cGMP ability to activate PKG, as mirrored by a reduced ability to phosphorylate VASP at serine 239 and to activate phosphodiesterase 5 [168]. Interestingly, we also observed that VSMC from obese insulin-resistant Zucker $\mathrm{fa} / \mathrm{fa}$ rats also show higher levels of $\mathrm{O}_{2}{ }^{-}$, and that antioxidants prevent the multiple defects of the NO/cGMP/PKG pathway, whereas $\mathrm{H}_{2} \mathrm{O}_{2}$ reproduces these defects in VSMC from lean, insulin sensitive Zucker fa/+ rats [168]: these data support the pivotal role of oxidative stress in the reduced response to NO in this animal model of obesity and insulin resistance, and can explain the reduced endotheliumindependent relaxation observed by some authors in these animals in vivo [169].

Other investigations in animal models showed that increased proliferation and migration of VSMC are a main feature accounting for atherogenic arterial lesions in insulin resistant states $[170,171]$. In a rat model of obesity and type 2 diabetes mellitus, it has been described both a numerical increase and functional abnormalities in intimal VSMC and the occurrence of VSMC accumulation in atherosclerotic lesions, with a direct correlation between VSMC proliferation and insulin concentrations $[170,172,173]$; the involvement of endogenous cytokines (especially TNF- $\alpha$ ), and the receptors of advanced glycation end products (AGE) [RAGE] in neointimal formation in obese Zucker rats has been recently recognized [174].

These observations are clinically relevant for the insulin resistant patients who undergo revascularization procedures in coronary arteries and in other vascular districts [175-177], since VSMC migration and proliferation lead to excessive neointima formation, which is the primary mechanism responsible of restenosis [176]. It has also been observed that in patients with type 2 diabetes the compensatory hyperinsulinemia associated with insulin resistance strongly predicts neointimal VSMC proliferation [178], and that insulin resistance and endothelial dysfunction are independent predictors of early restenosis after coronary stenting in humans [179].

\section{Influence of Adipocytokines on Platelets and Vascular Smooth Muscle Cells in Obesity}

As previously mentioned, the altered pattern of adipocytederived hormones and cytokines is deeply involved in the chronic proinflammatory state characterizing patients with central obesity and partially accounts for their increased cardiovascular risk $[5-7,9-11,15,18]$.

Changes in adipocyte-derived factors enhance oxidative stress by activating oxidases, interfere with $\mathrm{NO}$ availability and influence cell proliferation and apoptosis [91, 171, 180, $181]$.

Several evidences indicated that adipokines and cytokines influence platelet production and responses and VSMC function. In this part of the paper we will focus on the effects of the different adipocytokines on these cells deeply involved in atherogenesis and atherothrombosis.

5.1. Interleukin-6 (IL-6). Interleukin-6 (IL-6) is a multifunctional proinflammatory cytokine produced by different cell types, including those present in adipose tissue $[174,182]$ : adipose tissue, in particular, contributes to up to $35 \%$ of circulating IL-6 levels [174].

In healthy individuals IL-6 expression is due to a tight regulation dependent on a complex hormonal network related to glucocorticoid and catecholamine secretion [182, 183].

Increased IL-6 expression and circulating levels have been associated with a variety of diseases, including metabolic and vascular diseases, such as central obesity, the metabolic syndrome, type 2 diabetes mellitus, atherosclerosis and, in particular, atherosclerotic coronary artery disease $[182,183]$.

IL-6 - together with other cytokines-is a key risk factor for the development of atherothrombotic diseases due to its effect in plaque development and destabilization via release of other proinflammatory cytokines, oxidation of lipoproteins by phospholipases, stimulation of acute phase protein secretion, release of prothrombotic mediators, and activation of MMPs $[183,184]$. Moreover, the increased ROS formation by vascular enzyme systems under proinflammatory conditions may play a critical role in the cross talk between IL-6 and other vasoactive substances, such as Ang II and catecholamines [185-187].

5.1.1. IL-6 and Platelets. As far as megakaryocytopoiesis is concerned, IL-6 acts synergistically with thrombopoietin (TPO), other interleukins, and growth factors in promoting the maturation of megakaryocyte precursors [188-192]; actually, in vivo administration of IL-6 to humans increases circulating platelet counts $[190,192]$. This effect may explain the association between the increased markers of chronic inflammation and the elevated platelet count in obese women [193]: this phenomenon has been considered prothrombotic, since higher platelet counts are associated with adverse clinical outcomes in patients with acute coronary events [194].

As summarized in Figure 4, IL-6 is responsible of an acute prothrombotic state $[184,195]$ through mechanisms involving: (a) increased expression of TF, fibrinogen, factor VIII and vWF; (b) activation of endothelial cells; (c) reduced levels of hemostasis inhibitors, such as antithrombin and protein S [195]. Furthermore, IL-6 influences platelet function 


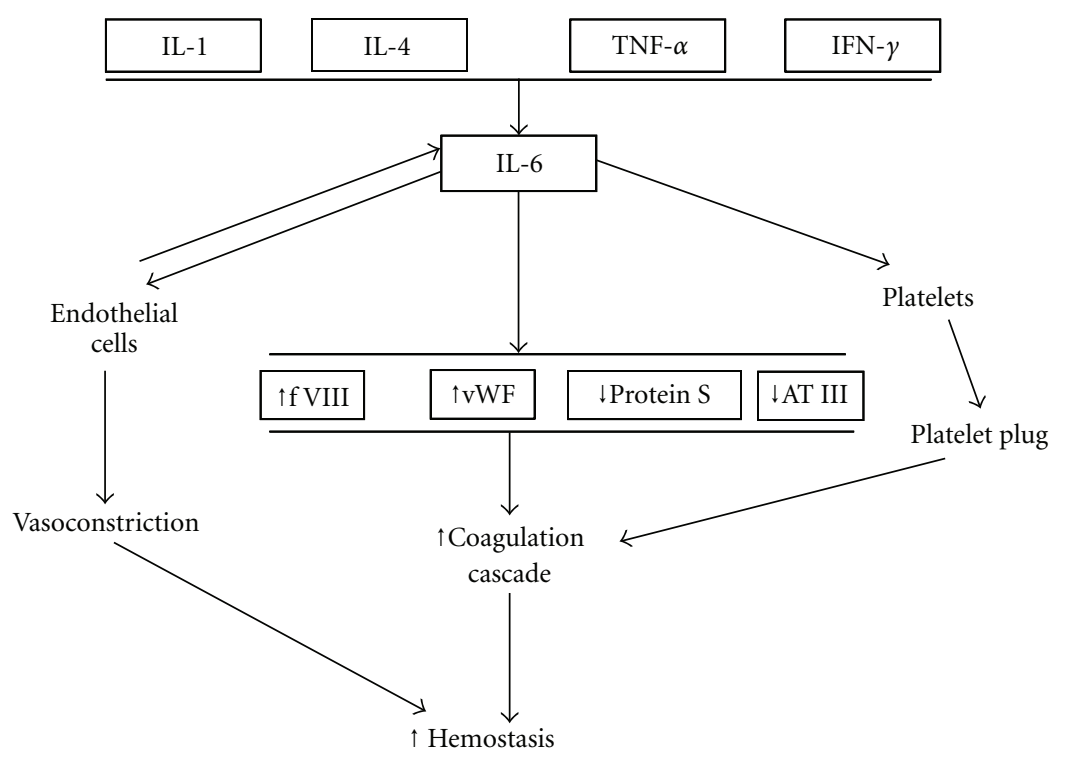

FIGURE 4: Mechanisms involved in the alterations of the coagulative balance induced by interleukin-6 (IL-6). IL-1, interleukin-1; IL-4, interleukin-4; TNF- $\alpha$, tumor necrosis factor- $\alpha$; IFN- $\gamma$, interferon- $\gamma$; f VIII, factor VIII, vWF, von Willebrand factor; AT III, antithrombin III.

by enhancing thrombin-induced activation [195], and modulates platelet responses by increasing ROS production [174].

5.1.2. IL-6 and VSMC. IL-6 influences both vessel wall cells and their progenitors; beyond its effects on resident endothelial cells, IL- 6 exerts pro-angiogenic actions by stimulating migration and proliferation of circulating endothelial progenitors [196].

As far as VSMC are concerned, proinflammatory mediators increase in these cells synthesis and release of IL-6 [197]. Additionally, IL-6 exerts specific effects on VSMC: in particular, it is involved in growth factor-dependent VSMC migration, by interplaying with VEGF and TNF- $\alpha$ [198-200], and stimulates VSMC proliferation with PDGFdependent and -independent mechanisms [201, 202].

These effects explain the clinical observation that increased IL-6 levels both in coronary and systemic circulation are a risk factor for restenosis after angioplasty $[203,204]$.

5.2. Tumor Necrosis Factor- $\alpha$ (TNF- $\alpha$ ). TNF- $\alpha$ is a pleiotropic, proinflammatory cytokine, produced as $17 \mathrm{kDa}$ protein and secreted as a $51 \mathrm{kDa}$ trimer by a variety of cells including not only adipose tissue (see below) but also macrophages, natural killer cells, T-cells, endothelial cells and VSMC [205]; its presence has been also recognized in human atheroma [206].

Adipose tissue has been identified as one of the main sources of TNF- $\alpha$ : the majority of TNF- $\alpha$ produced in adipose tissue is derived from infiltrating macrophages and not from mature adipocytes $[8,13-15,207]$.

Several studies evidenced an increased TNF- $\alpha$ circulating level both in obese nondiabetic subjects and in type 2 diabetic patients [13, 207-209] and hypothesized its involvement in the pathogenesis of obesity-linked insulin resistance [209-212].

As far as the TNF- $\alpha$ effects on vascular function are concerned, it has been observed that acute administration of TNF- $\alpha$ exerts per se a vasodilatory effect, but impairs endothelium-dependent vasodilation in response to insulin and acetylcholine in healthy humans [212-214]; furthermore, it inhibits the vasodilating actions of insulin in vessels of rat skeletal muscle [213-215]; the TNF- $\alpha$ interference with endothelial-mediated vasodilation is also due to shortening the half-life of eNOS mRNA in endothelial cells $[215,216]$ and to the increase of ET-1 synthesis and spillower [216].

TNF- $\alpha$ induces inflammatory changes in vessel wall by activating the transcription factor Nuclear factor- $\kappa \beta$ (NF$\kappa$ B) [217], which increases the expression of ICAM- 1 and VCAM-1, and the production of MCP-1 and M-CSF from endothelial cells and VSMC.

Plasma TNF- $\alpha$ concentrations predict vascular damage, since they are associated with early atherosclerosis in middleaged healthy men [218]; furthermore, elevations of TNF- $\alpha$ in the stable phase after myocardial infarction were associated with an increased risk of recurrent coronary events [219].

5.2.1. TNF- $\alpha$ and Platelets. In vitro studies showed that TNF$\alpha$ promotes platelet aggregation [220] and ROS production mainly through activation of the arachidonic acid pathway $[221,222]$.

Other data indicate that TNF- $\alpha$ influences platelet function also by increasing the secretion of leptin, which acts as proaggregating hormone.

At present, the results from in vivo studies are not conclusive and there are not evidences to identify TNF- $\alpha$ as a prothrombotic or antithrombotic factor in human patients [223]. 
5.2.2. TNF- $\alpha$ and VSMC. Human VSMC are both source and target of TNF- $\alpha$ [205] which, together with interferon- $\gamma$ and IL-1, stimulates IL- 6 production by this cell type [224]. Through NF- $\kappa$ B pathway, TNF- $\alpha$ increases synthesis/release of MMP from VSMC [217]. Thus, TNF- $\alpha$ is deeply involved in plaque inflammation and instabilization also by the mechanisms involving VSMC as described in the first part of this review.

5.3. Leptin. Leptin is a 167 -amino acid adipokine, primarily synthesized and released by mature adipocytes, although expressed also in many other tissues including muscle, placenta and gastric epithelium. Its circulating levels are highly correlated with BMI [225].

Leptin receptors have been identified both in the hypothalamus and in extrahypothalamic tissues and its main role is to inform the brain regarding the amount of stored fat, thus primarily regulating food intake and energy expenditure [226]; however, in obese humans increased leptin levels are unable to induce weight loss: this phenomenon is attributed to a selective resistance to its metabolic actions [227].

Leptin, which has a structural and functional relation to proinflammatory cytokines such as IL-6, also influences angiogenesis, inflammation, arterial blood pressure and secretion of other adipokines [10, 180, 181, 207].

In animal models, chronic hyperleptinemia is involved in oxidative stress by decreasing plasma levels of the antioxidant enzyme paraoxonase-1, an activity linked to circulating lipoproteins [228]. This leptin effect is followed by increased plasma and urinary concentration of isoprostanes reflecting an increased oxidative stress [228]. Evidences for an involvement of leptin in atherosclerosis have been recently provided by direct leptin administration in apolipoprotein deficient mice [229] and by the finding that ob/ob mice which lacked functioning leptin gene are resistant to atherosclerosis despite the presence of obesity and diabetes [230]. Also in humans, the vascular actions of leptin are considered proatherogenic and the increase of its circulating levels due to adiposity has been involved in the pathogenesis of vascular damage [231].

At present, clinical investigations considered leptin as an independent risk factor for cardiovascular [232-234] and cerebrovascular diseases [235, 236], evidencing that its plasma concentrations are independently associated with the intima-media thickness of the common carotid artery [237], and with the degree of coronary artery calcification in patients with type 2 diabetes mellitus, after controlling for adiposity and CRP $[238,239]$; furthermore, hyperleptinemia could be involved in the increased risk of postangioplasty restenosis $[179,240]$.

5.3.1. Leptin and Platelets. The pro-thrombotic actions of leptin in vivo are related to an influence on platelet function, and on coagulation/fibrinolysis balance, resulting in enhanced agonist-induced platelet aggregation and increased stability of arterial thrombi [241-243].

The long form of the leptin receptor $(\mathrm{Ob}-\mathrm{Rb})$ is present in human platelets and can be related to platelet activation by a specific pathway downstream of leptin-induced Janus kinase 2 (JAK2) activation including PI3-K and phospholipases $C \gamma_{2}$ and $A_{2}$, which influence cAMP hydrolysis, GPIIb/IIIa expression, and thromboxane synthesis [241]: these findings induced to consider circulating plaletets as a major target of leptin action, suggesting a possible direct link between obesity and thrombotic complication [241, 242].

Studies in vitro showed that leptin synergizes with subthreshold concentrations of agonists-such as ADP and thrombin - to induce platelet aggregation [242-245], but is unable to directly aggregate platelets. The involvement of leptin in the increased platelet activation in human obesity is not universally accepted, since recent studies provided conflicting results about platelet responsiveness to leptin in overweight and obesity [246, 247]; actually, in one study the effect of leptin on ADP-induced platelet aggregation is attenuated in obese individuals due to the receptor desensitization [245], whereas different results have been provided in another report [247].

Normal weight subjects undergoing complete caloric deprivation have an increased sensitivity of hemostatic responses to leptin [248]: this phenomenon indicates that the sensitivity of leptin receptors on platelet membranes is influenced by body composition [248]. In light of this, the resistance to leptin in overweight or obese patients could represent a protective mechanism against the excess pro-thrombotic stimulation produced by obesity-related hyperleptinemia [249].

However, other mechanisms by which leptin may contribute to vascular damage-such as inflammation, oxidative stress, endothelial dysfunction, as well as increased sympathetic tone-are preserved in obese subjects [240, 250252 ] and can contribute to pro-thrombotic action of leptin [240, 253].

5.3.2. Leptin and VSMC. Leptin exerts hemodynamic actions, even though its effects on the arterial wall have not been fully elucidated at present. Evidences in animals and humans showed that leptin administration induces acute vasodilation in different vascular districts, including human coronary arteries [207, 254, 255].

The involvement of a receptor-mediated NO release from endothelium has been shown in several, but not all, experimental models of leptin-induced vasodilation [255, 256]; despite the increase of NO release, acute leptin administration induced blood pressure reduction only in sympathectomized animals, likely for a compensatory activation of the sympathetic nervous system [256, 257]. Insulin interacts with leptin to modulate vascular responses, mainly by enhancing NO production by endothelium [258].

Due to the presence of active receptors in VSMC [259], leptin induces VSMC migration, proliferation, and expression of MMP-2, as shown in human aorta in vitro [260]; furthermore, in vitro studies showed that leptin stimulates osteoblastic differentiation of VSMC and hydroxyapatite production, thus explaining the relationships between circulating levels of leptin and the degree of coronary artery calcification $[238,239,261]$. 
Indirect mechanisms responsible of other leptin effects on VSMC are referred to oxidative stress which can cause endothelial or VSMC damage and stimulation of low-grade vascular inflammation [262].

5.4. Adiponectin. Adiponectin is a $30-\mathrm{kDa}$ protein collagenlike molecule that shares substantial homology with subunits of complement factor C1q [207, 263, 264]. It is expressed almost exclusively in mature adipocytes where is the most abundant adipokine synthesized and released locally and in the blood stream. It accounts for $0.01 \%$ of the total plasma proteins in form of trimer, hexamer and high molecular weight 12-to 18-mer [207, 263,264]. Adiponectin synthesis is detectable also in human and murine cardiomyocytes [265].

As opposite to the other adipokines, circulating adiponectin is negatively related to the increase of fat mass likely owing to the abnormal hormonal milieu mainly caused by the inhibitory effects exerted by the increased local TNF- $\alpha$ levels, by the oxidative stress and by the proinflammatory state which prevail in central obesity [207, 264, 266, 267]; its secretion is restored as a consequence of weight loss [267].

Adiponectin exerts insulin-sensitizing effects by increasing glucose uptake, NO production, and free fatty acid oxidation [268-270] and shows an antiinflammatory activity mainly through a cAMP-mediated interference with NF- $\kappa$ B signaling [271].

In vascular wall, the antiinflammatory properties of adiponectin — which account for its antiatherogenic effectsreduce cell expression of adhesion molecules and scavenger receptors $[272,273]$. This phenomenon is mediated by the inhibition of the effects of TNF- $\alpha$ and Ang II on both endothelial cells (expression of adhesion molecules, protection, increase of permeability, production of ROS) and macrophages (decrease of cytokine production mediated by NF- $\kappa$ B signaling) $[268,271,272]$.

The vasculo-protective effects of adiponectin have been recently confirmed in clinical studies, by showing that its decreased levels contribute to the metabolic and vascular abnormalities in obese subjects $[264,268,274]$.

5.4.1. Adiponectin and Platelets. In animals adiponectin plays a role as antithrombotic factor [275]. Actually, there is an accelerated thrombus formation after carotid arterial injury in adiponectin knockout mice in comparison to wildtype ones: the potential involvement of platelets in this effect is suggested by the presence of active adiponectin receptors AdipoR1 and AdipoR2 in wild-type mice and by the enhanced platelet response to ADP and collagen in adiponectin knockout animals [275]. The same receptors are present in isolated human platelets and in human megakaryocytic cell lines; in humans, however, adiponectin does not influence platelet activation by ADP and collagen [276].

It has been hypothesized that adiponectin exerts indirect anti-thrombotic effects by decreasing the circulating concentrations of TNF- $\alpha$ and IL- 6 and by interfering with their pro-thrombotic activities, mainly dependent on increased oxidative stress and decreased NO bioavailability [20, 277, 278].

5.4.2. Adiponectin and VSMC. Adiponectin suppresses proliferation and migration of smooth muscle cells by directly binding to several growth factors, particularly PDGF BB, FGF, and heparin-binding epidermal growth factor-like growth factor (HB-EGF) $[279,280]$.

Following experimental vascular injury, immunohistochemical analysis shows the presence of adiponectin in the walls of the catheter-injured vessels but not in intact vascular walls [281]; thus, it can be hypothesized that adiponectin secreted from adipose tissue reaches the injured arteries after the lesion of the endothelial barrier and accumulates in vascular walls, thus reducing the atherogenic process [281].

Finally, adiponectin may favor plaque stabilization decreasing MMP activity by modulating the expression of the Tissue Inhibitor of Metalloproteinase-1 (TIMP-1) through increased IL-10 secretion [282].

5.5. Ghrelin. Ghrelin is a 28 -amino acid peptide hormone, predominantly produced by the stomach [283], which acts as a natural ligand of the Growth Hormone $(\mathrm{GH})$ secretagogue (GHS) receptor type 1a (GHS-R1a), and plays a role in the central control of appetite together with leptin [284]. Circulating ghrelin levels are inversely related with degree of obesity evaluated by BMI [285].

More recently, it has been demonstrated that ghrelin also influences the cardiovascular system, by decreasing sympathetic activity and producing vasodilation through an endothelium-independent mechanism [286].

Furthermore, ghrelin exerts antiinflammatory effects in vessels, improves left ventricular function and shows antiapoptotic actions on cardiomyocytes [286].

It has been suggested that the decrease of ghrelin in obese patients is involved in their enhanced cardiovascular risk and that ghrelin administration exerts protective effects in patients with obesity-related metabolic syndrome [287].

5.5.1. Ghrelin and Platelets. The protective cardiovascular effects of ghrelin likely do not involve platelets, since in vitro this hormone does not affect platelet aggregation or adhesion [276].

5.5.2. Ghrelin and VSMC. VSMC are targets of ghrelin, which inhibits in vitro Ang II-induced proliferation and contraction in a dose-response manner via the cAMP/PKA pathway [288], and prevents vascular calcification in rats [289].

5.6. Apelin. Apelin is an endogenous peptide ligand for the orphan G-coupled APJ receptor, which exhibits close homology with the angiotensin-like 1 receptor [290]. It exists at least in three molecular forms, consisting of 13,17, or 36 amino acids, all originating from a common 77-amino acid precursor, and is present in several tissues, primarily in the vascular endothelium [290]. Recently, apelin has been identified in adipose tissue [291], where its gene expression 
is increased by insulin, steroids and TNF- $\alpha$ [292, 293]. Its synthesis and release are up-regulated in obesity, whereas its expression in adipose tissue and its circulating levels are reduced by weight loss [292].

Apelin is mainly considered a vascular hormone: actually, it induces an endothelium-dependent vasodilation [294, 295], exerts inotropic effects [296], and plays a protective role in the pathogenesis of heart failure by modulating the harmful effects of Ang II [294, 295].

Apelin is down-regulated in patients with heart failure and up-regulated by a favourable left ventricular remodeling [295].

The role of apelin-APJ system in atherogenesis is controversial. Some apelin actions-including modulation of endothelial oxidative stress and macrophage activation, NOdependent vasorelaxation and reduction of arterial blood pressure $[295,297,298]$ — are clearly protective, whereas other effects on arterial vessels might be detrimental by favouring the atherogenic damage [299].

5.6.1. Apelin and VSMC. In the vascular system, the apelinAPJ system is expressed in both endothelium-where it is mitogenic [300] —and in VSMC [301]. Acute apelin administration in man causes $\mathrm{NO}$-mediated arteriolar vasodilation [294]. At present, data about the direct effects of apelin on VSMC are incomplete; it has been suggested an influence on myosin light chain phosphorylation via APJ receptors, responsible of vasoconstriction [302], and a proliferative effect on VSMC, induced by oxidative stress [299, 303].

5.7. Visfatin. Visfatin, previously recognized as a protein involved in immune B-cell maturation [pre-B cell colonyenhancing factor (PBEF)] [304], is abundantly expressed in visceral adipose tissue and is up-regulated in some, but not in all, the animal models of obesity [305]. Preliminary studies suggest that plasma visfatin concentrations are increased in humans affected by abdominal obesity and type 2 diabetes mellitus [306, 307].

Although it is not a cytokine, visfatin expression is up-regulated by cytokines: several studies showed its involvement in metabolic and vascular homeostasis [308, 309]. Metabolic insulinomimetic effects, characterized by reduction of hepatic glucose production and stimulation of peripheral glucose utilization, has been attributed to binding to insulin receptor at a site different from that of insulin [308], even though recent results excluded a visfatin-dependent direct activation of insulin signaling pathway and attributed its action to nicotinamide phosphoribosyltransferase activity (Nampt) [310]. Vascular effects are both chronic and acute (see Figure 5): chronic exposure to high visfatin concentrations-such as in obesity and in type 2 diabetes mellitus-promotes endothelial dysfunction, angiogenesis and atherosclerotic plaque instabilization, whereas acute visfatin administration stimulates eNOS expression and activity in endothelial cells [309] and directly protects cardiomyocytes against the detrimental effects of acute ischemia-reperfusion injury [311].
5.7.1. Visfatin and VSMC. Visfatin influences VSMC phenotype maturation from a proliferative noncontractile to a nonproliferative contractile one required for vasomotor function [312], and promotes VSMC proliferation in perivascular adipose tissue by a paracrine mechanism [313].

5.8. Resistin. Resistin has been originally identified as an adipocyte-secreted peptide able to induce insulin resistance in rodents; in humans it is represented by a $12.5 \mathrm{kDa}$ cysteine-rich protein of 108 amino acids [314]. Also in humans resistin is produced by adipose tissue and may act both in paracrine and in endocrine fashion [314]: however, in contrast to mice, only a low level of expression of resistin has been found in mature adipocytes in humans $[315,316]$. Furthermore, resistin expression has been demonstrated in bone marrow, trophoblastic cells of placenta, pancreas, synovial tissue, and circulating blood cells [317].

Resistin is an important regulator of glucose homeostasis, adipogenesis, and, potentially, inflammation [317]; in particular, it can induce insulin resistance by regulating adipose tissue deposition through a negative feedback mechanism [317], and exerts proinflammatory effects through activation of the transcription factor NF- $\kappa$ B [318].

The interplay between resistin and vascular wall cells can potentially contribute to the development of atherosclerotic lesions (Figure 6): in particular, it favors angiogenesis by inducing endothelial cell growth activation and migration, mainly by increasing ET-1 release $[319,320]$, and potentiating the effect of CD40L [321]; furthermore, it is involved in lipid storage in macrophages [317, 322].

5.8.1. Resistin and VSMC. Resistin induces proliferation of cultured human aortic VSMC through both ERK 1/2 and Akt signaling pathways [323]. Furthermore, hypoxia increases resistin expression in cultured rat VSMC [323].

5.9. Endothelin. Increased circulating levels of ET-1 have been observed in patients affected by central obesity and metabolic syndrome [324]. ET-1 elevation is proportional to hyperinsulinemia $[324,325]$, and weight loss by diet intervention reduces both serum insulin and ET-1 [326].

The increase of ET-1 accounts for a prevailing vasoconstrictive effect of insulin in insulin resistant states, in which the insulin-induced, PI3-K-mediated increase of NO is impaired [325]; furthermore, ET-1 contributes per se to vasoconstriction by influencing calcium fluxes, by activating the renin-angiotensin system, and by inducing VSMC hypertrophy [327].

5.9.1. ET-1 and Platelets. Platelets are a potential target of circulating ET-1. However, as recently reviewed, ET-1 effects on platelets are still conflicting [328]: some studies showed that in vitro exposure to ET-1 induces platelet activation or increases platelet responses to aggregating agonists [327329], other studies, however, failed to detect any direct effect [329] or even showed a decrease in platelet responses [328].

These conflicting results may be due to complex interactions between platelet $\mathrm{ET}(\mathrm{A})$ and $\mathrm{ET}(\mathrm{B})$ receptors. 
Acute and chronic cardiovascular effects of visfatin

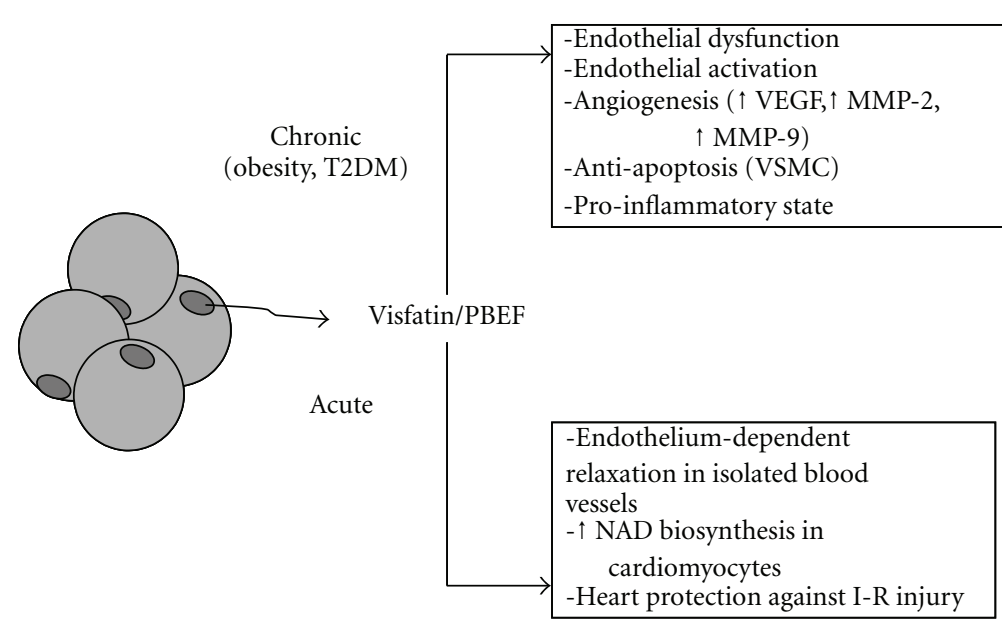

FIGURE 5: Acute and chronic cardiovascular effects of visfatin. VEGF, vascular endothelial growth factor; MMP-2, matrix metalloproteinase2; MMP-9, matrix metalloproteinase-9; PBEF, pre-B cell colony-enhancing factor I-R, ischemia-reperfusion.

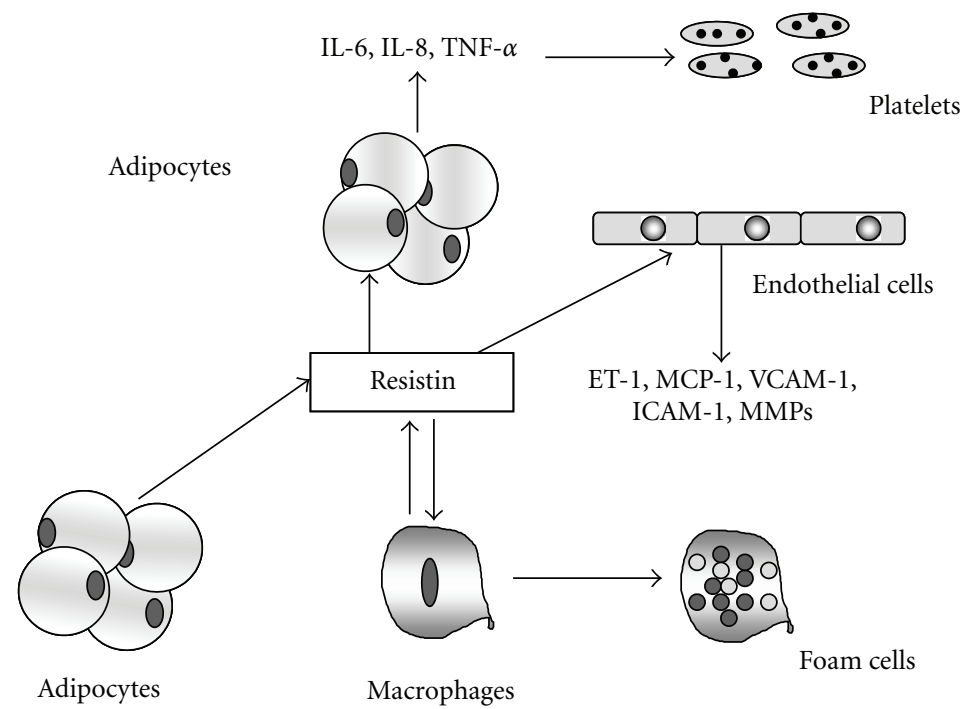

FIGURE 6: Potential vascular effects of resistin. IL-6, interleukin-6; IL-8, interleukin-8; TNF- $\alpha$, tumor necrosis factor- $\alpha$; ET-1, endothelin-1; MCP-1, monocyte chemoattractant protein-1; VCAM-1, Vascular Cell Adhesion Molecule-1; ICAM-1, Intercellular Adhesion Molecule-1; MMPs, matrix metalloproteinases.

5.9.2. ET-1 and VSMC. VSMC are both a source and a target of ET-1 [330-333]. As recently reviewed [333], ET-1 stimulates VSMC proliferation [334], migration [335], contraction [336], extracellular matrix synthesis and remodeling $[337,338]$, and expression of other proatherogenic growth factors such as PDGF and TGF- $\beta$ [339].

\section{Conclusions}

The major adverse consequences of central obesity are related to the development of type 2 diabetes mellitus and of atherothrombotic vascular diseases, which account for a high disease-related mortality $[1,5-7]$. As extensively confirmed, the main alterations of central obesity involved in vascular damage are recognized in the impaired systemic metabolic homeostasis as well as in the presence of an active low-grade chronic inflammatory process in tissues that are relevant for metabolism, such as adipose tissue, liver, muscle and arterial wall $[6,11,13,15,19,340]$.

In particular, the activation of an inflammatory process by adipose tissue is related to impairment of the secretion pattern of adipocytokines, including increased local availability of major cytokines $[6,7,13,14,18,340,341]$, as well as enhanced synthesis and secretion of proinflammatory adipokines [13-15] and reduced availability of protective, insulin sensitizing peptides, including adiponectin and ghre$\operatorname{lin}[2,15,340-343]$. 
On the basis of the large number of reviewed studies, a relevant role can be recognized to impairment of platelet and VSMC functions in the pro-thrombotic tendency, proinflammatory state and accelerated atherogenesis of the patients with central obesity [20-22].

Impaired synthesis and/or secretion of single adipocytokines which can interplay with platelets and VSMC are deeply involved in these phenomena.

As extensively reviewed, a large body of evidences showed detrimental actions of the increased synthesis and secretion of several mediators which act through pro-thrombotic and proliferative actions and oxidative stress, including TNF- $\alpha$, interleukins and likely leptin [342]. However, also the lack of the protective effects of adipokines such as adiponectin and ghrelin has to be considered another relevant feature of the proatherogenic milieu characterizing the altered endocrine pattern of the patients with central obesity. In particular, adiponectin is a relevant anti-thrombotic adipokine, as widely reviewed $[266,268,343]$ and emerging evidences underline ghrelin protective effects on insulin resistance, cardiovascular system, oxidative stress, and, likely, hemostatic balance $[20,104,105,343]$ : therefore, the reduced levels of this peptide in central obesity may be another deterimental feature increasing cardiovascular risk in obese subjects.

In summary, available evidences allow to hypothesize the presence of a complex scenario related to increased atherogenic and atherothrombotic risk in central obesity: in this context an impaired pattern of adipocytokine synthesis and secretion, rather than alteration of single mediators, has to be considered a major mechanistic link.

\section{Review Strategy and Selection Criteria}

Searches for original articles and reviews from 1985 to February 2010 focusing on obesity, hemostasis, vascular function and adipokines were performed in MEDLINE and PubMed electronic databases. The search terms were: "adipocytokines", “adipokines", “adiponectin”, “apelin", “cytokines", "central obesity", "endothelin-1", "ghrelin", "insulin resistance", "interleukin-6", "leptin", "metabolic syndrome", "obesity", "overweight", "platelets", "platelet dysfunction", "resistin", "thrombosis", "Tumor necrosis factor- $\alpha$ ", "vascular smooth muscle cells", and "visfatin". All papers identified were English-language, full-text papers and were selected on the basis of relevance and novelty; a priority was given to those published in peer-reviewed journals.

\section{Abbreviations}

$\begin{array}{ll}\text { ADP: } & \text { Adenosine 5-diphosphate } \\ \text { AGE: } & \text { Advanced glycation end products } \\ \text { Akt/PKB: } & \text { Akt/protein kinase B } \\ \text { Ang II: } & \text { Angiotensin II } \\ \text { BMI: } & \text { Body mass index } \\ \text { cAMP: } & \text { 3', } 5^{\prime} \text {-cyclic adenosine monophosphate } \\ \text { CD40L: } & \text { CD40 ligand } \\ \text { cGMP: } & \text { 3',5'-cyclic guanosine monophosphate } \\ \text { COX-1: } & \text { Cyclo-oxygenase-1 } \\ \text { CRP: } & \text { C-reactive protein }\end{array}$

DAG: Diacylcyglycerol

EGF: Epidermal Growth Factor

eNOS: $\quad$ Endothelial NO synthase

ERK 1/2: $\quad$ Extracellular signal regulated kinases

ET-1: $\quad$ Endothelin-1

FACoA: $\quad$ Fatty acid coenzyme A

FFA: $\quad$ Free fatty acids

FGF: $\quad$ Fibroblast Growth Factor

$\mathrm{H}_{2} \mathrm{O}_{2}$ : $\quad$ Hydrogen peroxide

HSP-20: $\quad 20-\mathrm{kDa}$ heat shock-related protein

HSP-90: Heat shock protein-90

HIF-1: $\quad$ Hypoxia Inducible Factor-1

ICAM-1: Intercellular Adhesion Molecule-1

IGF-1: $\quad$ Insulin-like Growth Factor-1

IL-1: $\beta \quad$ Interleukin-1 $\beta$

IL-6: $\quad$ Interleukin-6

IP3: Inositol, 1,4,5-triphosphate

IRS: Insulin Receptor Substrates

8-iso- -GF $_{2 \alpha}: 8$-iso-prostaglandin- $\mathrm{F}_{2 \alpha}$

LDL: $\quad$ Low density lipoproteins

MAPK: $\quad$ Mitogen-Activated Protein Kinase

MCP-1: $\quad$ Monocyte Chemoattractant Protein-1

MIF: $\quad$ Macrophage migration inhibitory factor

MMPs: $\quad$ Matrix metalloproteinases

MPV: $\quad$ Mean platelet volume

NF-B $\kappa$ : Nuclear Factor- $\kappa$ B

NO: $\quad$ Nitric oxide

$\mathrm{O}_{2}^{-}: \quad$ Superoxide anion

PAF: $\quad$ Platelet activating factor

PAI-1: $\quad$ Plasminogen Activator Inhibitor-1

PBEF: $\quad$ Pre-B cell colony-enhancing factor

PDGF: $\quad$ Platelet-derived growth factor

PF-4: $\quad$ Platelet factor-4

PGI: $\quad$ Prostacyclin

PI3-K: $\quad$ Phosphatidylinositol 3-kinase

PIP: $\quad$ Phosphatidylinositol 4,5-bisphosphate

PKC: $\quad$ Protein kinase C

PKG: $\quad$ cGMP-dependent protein kinase

PPAR: $\quad$ Peroxisome proliferator-activated receptor

RAGE: $\quad$ Receptors of advanced glycation end products (AGE)

RANTES: Regulated on activation, normal T-cell expressed and secreted

ROS: $\quad$ Reactive oxygen species

sGC: $\quad$ Soluble guanylate cyclase

TF: $\quad$ Tissue factor

TGF- $\beta$ : $\quad$ Transforming growth factor- $\beta$

TIMP-1: $\quad$ Tissue Inhibitor of Metalloproteinase-1

TNF- $\alpha$ : Tumor necrosis factor- $\alpha$

TPO: $\quad$ Thrombopoietin

TXA: $\quad$ Thromboxane $\mathrm{A}_{2}$

u-PA: $\quad$ Urokinase plasminogen activator

VASP: $\quad$ Vasodilatory-Stimulated

Phosphoprotein

VCAM-1: Vascular Cell Adhesion Molecule-1

VEGF: Vascular Endothelial Growth Factor

VIP: $\quad$ Vasoactive Intestinal Polypeptide

VSMC: Vascular smooth muscle cells

vWF: $\quad$ Von Willebrand factor. 


\section{Acknowledgments}

This study was supported by a grant from Italian Ministero dell'Istruzione, Università e Ricerca (MIUR) COFIN 2004 within the project "The molecular basis of insulin resistance and their importance in the pathogenesis of the alterations of the vessel wall," Local Coordinator: Giovanni Anfossi, National Coordinator: Amalia Bosia and by two grants from Regione Piemonte to Giovanni Anfossi (years 2004 and 2006) and to Mariella Trovati (years 2007 and 2008).

\section{References}

[1] S. Yusuf, S. Hawken, S. Ôunpuu, L. Bautista, M. G. Franzosi, P. Commerford, C. C. Lang, Z. Rumboldt, C. L. Onen, L. Lisheng, S. Tanomsup, P. Wangai Jr., F. Razak, A. M. Sharma, and S. S. Anand, "Obesity and the risk of myocardial infarction in 27000 participants from 52 countries: a casecontrol study," The Lancet, vol. 366, no. 9497, pp. 1640-1649, 2005.

[2] H. E. Lebovitz and M. A. Banerji, "Point: visceral adiposity is causally related to insulin resistance," Diabetes Care, vol. 28, no. 9, pp. 2322-2325, 2005.

[3] S. Klein, D. B. Allison, S. B. Heymsfield, D. E. Kelley, R. L. Leibel, C. Nonas, and R. Kahn, "Waist circumference and cardiometabolic risk: a consensus statement from Shaping America's Health: association for Weight Management and Obesity Prevention; NAASO, the Obesity Society; the American Society for Nutrition; and the American Diabetes Association," Diabetes Care, vol. 30, no. 6, pp. 1647-1652, 2007.

[4] K. G. M. M. Alberti, R. H. Eckel, S. M. Grundy, P. Z. Zimmet, J. I. Cleeman, K. A. Donato, J.-C. Fruchart, W. P. T. James, C. M. Loria, and S. C. Smith, "Harmonizing the metabolic syndrome: a joint interim statement of the international diabetes federation task force on epidemiology and prevention; National Heart, Lung, and Blood Institute; American Heart Association; World Heart Federation; International Atherosclerosis Society; and International Association for the Study of Obesity," Circulation, vol. 120, no. 16, pp. 16401645, 2009.

[5] G. Reaven, F. Abbasi, and T. McLaughlin, "Obesity, insulin resistance, and cardiovascular disease," Recent Progress in Hormone Research, vol. 59, pp. 207-223, 2004.

[6] L. F. Van Gaal, I. L. Mertens, and C. E. De Block, "Mechanisms linking obesity with cardiovascular disease," Nature, vol. 444, no. 7121, pp. 875-880, 2006.

[7] A. I. Kakafika, E. N. Liberopoulos, A. Karagiannis, V. G. Athyros, and D. P. Mikhailidis, "Dyslipidaemia, hypercoagulability and the metabolic syndrome," Current Vascular Pharmacology, vol. 4, no. 3, pp. 175-183, 2006.

[8] K. E. Wellen and G. S. Hotamisligil, "Obesity-induced inflammatory changes in adipose tissue," Journal of Clinical Investigation, vol. 112, no. 12, pp. 1785-1788, 2003.

[9] J. N. Fain, A. K. Madan, M. L. Hiler, P. Cheema, and S. W. Bahouth, "Comparison of the release of adipokines by adipose tissue, adipose tissue matrix, and adipocytes from visceral and subcutaneous abdominal adipose tissues of obese humans," Endocrinology, vol. 145, no. 5, pp. 2273 2282, 2004.

[10] H. Waki and P. Tontonoz, "Endocrine functions of adipose tissue," Annual Review of Pathology, vol. 2, pp. 31-56, 2007.
[11] Y. Matsuzawa, "Therapy insight: adipocytokines in metabolic syndrome and related cardiovascular disease," Nature Clinical Practice Cardiovascular Medicine, vol. 3, no. 1, pp. 35-42, 2006.

[12] S. P. Weisberg, D. McCann, M. Desai, M. Rosenbaum, R. L. Leibel, and A. W. Ferrante Jr., "Obesity is associated with macrophage accumulation in adipose tissue," Journal of Clinical Investigation, vol. 112, no. 12, pp. 1796-1808, 2003.

[13] G. S. Hotamisligil, "Inflammation and metabolic disorders," Nature, vol. 444, no. 7121, pp. 860-867, 2006.

[14] I. Harman-Boehm, M. Blüher, H. Redel, N. Sion-Vardy, S. Ovadia, E. Avinoach, I. Shai, N. Klöting, M. Stumvoll, N. Bashan, and A. Rudich, "Macrophage infiltration into omental versus subcutaneous fat across different populations: effect of regional adiposity and the comorbidities of obesity," Journal of Clinical Endocrinology and Metabolism, vol. 92, no. 6, pp. 2240-2247, 2007.

[15] M. W. Rajala and P. E. Scherer, "Minireview: the adipocyteat the crossroads of energy homeostasis, inflammation, and atherosclerosis," Endocrinology, vol. 144, no. 9, pp. 37653773, 2003.

[16] T. Suganami, J. Nishida, and Y. Ogawa, "A paracrine loop between adipocytes and macrophages aggravates inflammatory changes: role of free fatty acids and tumor necrosis factor a," Arteriosclerosis, Thrombosis, and Vascular Biology, vol. 25, no. 10, pp. 2062-2068, 2005.

[17] S. Umemura, N. Nyui, K. Tamura, K. Hibi, S. Yamaguchi, M. Nakamaru, T. Ishigami, M. Yabana, M. Kihara, S. Inoue, and M. Ish II, "Plasma angiotensinogen concentrations in obese patients," American Journal of Hypertension, vol. 10, no. 6, pp. 629-633, 1997.

[18] E. A. Francischetti and V. A. Genelhu, "Obesityhypertension: an ongoing pandemic," International Journal of Clinical Practice, vol. 61, no. 2, pp. 269-280, 2007.

[19] P. Calabro and E. T. H. Yeh, "Intra-abdominal adiposity, inflammation, and cardiovascular risk: new insight into global cardiometabolic risk," Current Hypertension Reports, vol. 10, no. 1, pp. 32-38, 2008.

[20] M.-C. Alessi and I. Juhan-Vague, "Metabolic syndrome, haemostasis and thrombosis," Thrombosis and Haemostasis, vol. 99, no. 6, pp. 995-1000, 2008.

[21] G. Anfossi, I. Russo, and M. Trovati, "Platelet dysfunction in central obesity," Nutrition, Metabolism and Cardiovascular Diseases, vol. 19, no. 6, pp. 440-449, 2009.

[22] G. Anfossi, I. Russo, G. Doronzo, and M. Trovati, "Contribution of insulin resistance to vascular dysfunction," Archives of Physiology and Biochemistry, vol. 115, no. 4, pp. 199-217, 2009.

[23] J. N. George, "Platelets," The Lancet, vol. 355, no. 9214, pp. 1531-1539, 2000.

[24] T. Junt, H. Schulze, Z. Chen, S. Massberg, T. Goerge, A. Krueger, D. D. Wagner, T. Graf, J. E. Italiano Jr., R. A. Shivdasani, and U. H. Von Andrian, "Dynamic visualization of thrombopoiesis within bone marrow," Science, vol. 317, no. 5845, pp. 1767-1770, 2007.

[25] D. Bluteau, L. Lordier, A. Di Stefano, Y. Chang, H. Raslova, N. Debili, and W. Vainchenker, "Regulation of megakaryocyte maturation and platelet formation," Journal of Thrombosis and Haemostasis, vol. 7, no. 1, pp. 227-234, 2009.

[26] M. Gawaz, H. Langer, and A. E. May, "Platelets in inflammation and atherogenesis," Journal of Clinical Investigation, vol. 115, no. 12, pp. 3378-3384, 2005. 
[27] S. Lindemann, B. Krämer, P. Seizer, and M. Gawaz, "Platelets, inflammation and atherosclerosis," Journal of Thrombosis and Haemostasis, vol. 5, no. 1, pp. 203-211, 2007.

[28] Z. M. Ruggeri and G. L. Mendolicchio, "Adhesion mechanisms in platelet function," Circulation Research, vol. 100, no. 12 , pp. 1673-1685, 2007.

[29] D. Varga-Szabo, I. Pleines, and B. Nieswandt, "Cell adhesion mechanisms in platelets," Arteriosclerosis, Thrombosis, and Vascular Biology, vol. 28, no. 3, pp. 403-413, 2008.

[30] J. Rivera, M. L. Lozano, L. Navarro-Núñez, and V. Vicente García, "Platelet receptors and signaling in the dynamics of thrombus formation," Haematologica, vol. 94, no. 5, pp. 700$711,2009$.

[31] J. T. B. Crawley, S. Zanardelli, C. K. N. K. Chion, and D. A. Lane, "The central role of thrombin in hemostasis," Journal of Thrombosis and Haemostasis, vol. 5, no. 1, pp. 95-101, 2007.

[32] S. Offermanns, "Activation of platelet function through G protein-coupled receptors," Circulation Research, vol. 99, no. 12, pp. 1293-1304, 2006.

[33] C. Gachet, "P2 receptors, platelet function and pharmacological implications," Thrombosis and Haemostasis, vol. 99, no. 3, pp. 466-472, 2008.

[34] N. Nakahata, "Thromboxane A2: physiology/pathophysiology, cellular signal transduction and pharmacology," Pharmacology \& Therapeutics, vol. 118, no. 1, pp. 18-35, 2008.

[35] B. S. Sachais, A. A.-R. Higazi, D. B. Cines, M. Poncz, and M. A. Kowalska, "Interactions of platelet factor 4 with the vessel wall," Seminars in Thrombosis and Hemostasis, vol. 30, no. 3, pp. 351-358, 2004.

[36] P. Blair and R. Flaumenhaft, "Platelet $\alpha$-granules: basic biology and clinical correlates," Blood Reviews, vol. 23, no. 4, pp. 177-189, 2009.

[37] G. Davì and C. Patrono, "Mechanisms of disease: platelet activation and atherothrombosis," The New England Journal of Medicine, vol. 357, no. 24, pp. 2482-2494, 2007.

[38] R. Ross, "Atherosclerosis-an inflammatory disease," The New England Journal of Medicine, vol. 340, no. 2, pp. 115126, 1999.

[39] H. F. Langer and M. Gawaz, "Platelet-vessel wall interactions in atherosclerotic disease," Thrombosis and Haemostasis, vol. 99, no. 3, pp. 480-486, 2008.

[40] F. Krötz, H.-Y. Sohn, and U. Pohl, "Reactive oxygen species: players in the platelet game," Arteriosclerosis, Thrombosis, and Vascular Biology, vol. 24, no. 11, pp. 1988-1996, 2004.

[41] C. A. Gleissner, P. von Hundelshausen, and K. Ley, "Platelet chemokines in vascular disease," Arteriosclerosis, Thrombosis, and Vascular Biology, vol. 28, no. 11, pp. 1920-1927, 2008.

[42] Z. M. Ruggeri, "Platelets in atherothrombosis," Nature Medicine, vol. 8, no. 11, pp. 1227-1234, 2002.

[43] Y. Huo and K. F. Ley, "Role of platelets in the development of atherosclerosis," Trends in Cardiovascular Medicine, vol. 14, no. 1, pp. 18-22, 2004.

[44] T. Nassar, B. S. Sachais, S. Akkawi, M. A. Kowalska, K. Bdeir, E. Leitersdorf, E. Hiss, L. Ziporen, M. Aviram, D. Cines, M. Poncz, and A. A.-R. Higazi, "Platelet factor 4 enhances the binding of oxidized low-density lipoprotein to vascular wall cells," Journal of Biological Chemistry, vol. 278, no. 8, pp. 6187-6193, 2003.

[45] G. van Kooten and J. Banchereau, "CD40-CD40 ligand," Journal of Leukocyte Biology, vol. 67, no. 1, pp. 2-17, 2000.

[46] R. P. Phipps, L. Koumas, E. Leung, S. Y. Reddy, T. Blieden, and J. Kaufman, "The CD40-CD40 ligand system: a potential therapeutic target in atherosclerosis," Current Opinion in Investigational Drugs, vol. 2, no. 6, pp. 773-777, 2001.

[47] F. Santilli, S. Basili, P. Ferroni, and G. Davì, "CD40/CD40L system and vascular disease," Internal and Emergency Medicine, vol. 2, no. 4, pp. 256-268, 2007.

[48] C. Antoniades, C. Bakogiannis, D. Tousoulis, A. S. Antonopoulos, and C. Stefanadis, "The CD40/CD40 ligand system: linking inflammation with atherothrombosis," Journal of the American College of Cardiology, vol. 54, no. 8, pp. 669-677, 2009.

[49] K. S. S. Prasad, P. Andre, M. He, M. Bao, J. Manganello, and D. R. Phillips, "Soluble CD40 ligand induces $\beta 3$ integrin tyrosine phosphorylation and triggers platelet activation by outside-in signaling," Proceedings of the National Academy of Sciences of the United States of America, vol. 100, no. 21, pp. 12367-12371, 2003.

[50] M. Poggi, J. Jager, O. Paulmyer-Lacroix, F. Peiretti, T. Gremeaux, M. Verdier, M. Grino, A. Stepanian, S. Msika, R. Burcelin, D. De Prost, J. F. Tanti, and M. C. Alessi, "The inflammatory receptor CD40 is expressed on human adipocytes: contribution to crosstalk between lymphocytes and adipocytes," Diabetologia, vol. 52, no. 6, pp. 1152-1163, 2009.

[51] V. Henn, J. R. Slupsky, M. Gräfe, I. Anagnostopoulos, R. Förster, G. Müller-Berghaus, and R. A. Kroczek, "CD40 ligand on activated platelets triggers an inflammatory reaction of endothelial cells," Nature, vol. 391, no. 6667, pp. 591-594, 1998.

[52] G. Desideri and C. Ferri, "Effects of obesity and weight loss on soluble CD40L levels," Journal of the American Medical Association, vol. 289, no. 14, pp. 1781-1782, 2003.

[53] K. Gokulakrishnan, R. Deepa, V. Mohan, and M. D. Gross, "Soluble P-selectin and CD40L levels in subjects with prediabetes, diabetes mellitus, and metabolic syndrome-the Chennai Urban Rural Epidemiology Study," Metabolism, vol. 55, no. 2, pp. 237-242, 2006.

[54] F. Angelico, C. Alessandri, D. Ferro, P. Pignatelli, M. Del Ben, S. Fiorello, R. Cangemi, L. Loffredo, and F. Violi, "Enhanced soluble CD40L in patients with the metabolic syndrome: relationship with in vivo thrombin generation," Diabetologia, vol. 49, no. 6, pp. 1169-1174, 2006.

[55] C. Natal, P. Restituto, C. Iñigo, I. Colina, J. Díez, and N. Varo, "The proinflammatory mediator CD40 ligand is increased in the metabolic syndrome and modulated by adiponectin," Journal of Clinical Endocrinology and Metabolism, vol. 93, no. 6, pp. 2319-2327, 2008.

[56] P. von Hundelshausen, K. S. C. Weber, Y. Huo, A. E. I. Proudfoot, P. J. Nelson, K. Ley, and C. Weber, "RANTES deposition by platelets triggers monocyte arrest on inflamed and atherosclerotic endothelium," Circulation, vol. 103, no. 13, pp. 1772-1777, 2001.

[57] J. Simak and M. P. Gelderman, "Cell membrane microparticles in blood and blood products: potentially pathogenic agents and diagnostic markers," Transfusion Medicine Reviews, vol. 20, no. 1, pp. 1-26, 2006.

[58] K. T. Tan and G. Y. H. Lip, "The potential role of platelet microparticles in atherosclerosis," Thrombosis and Haemostasis, vol. 94, no. 3, pp. 488-492, 2005.

[59] J. Polasek, "Procoagulant potential of platelet $\alpha$ granules," Platelets, vol. 15, no. 7, pp. 403-407, 2004.

[60] M. Merten, R. Pakala, P. Thiagarajan, and C. R. Benedict, "Platelet microparticles promote platelet interaction with subendothelial matrix in a glycoprotein IIb/IIIa-dependent 
mechanism," Circulation, vol. 99, no. 19, pp. 2577-2582, 1999.

[61] S. Lindemann, N. D. Tolley, D. A. Dixon, T. M. McIntyre, S. M. Prescott, G. A. Zimmerman, and A. S. Weyrich, "Activated platelets mediate inflammatory signaling by regulated interleukin $1 \beta$ synthesis," Journal of Cell Biology, vol. 154, no. 3, pp. 485-490, 2001.

[62] S. Massberg, F. Vogt, T. Dickfeld, K. Brand, S. Page, and M. Gawaz, "Activated platelets trigger an inflammatory response and enhance migration of aortic smooth muscle cells," Thrombosis Research, vol. 110, no. 4, pp. 187-194, 2003.

[63] S. F. Mause, P. von Hundelshausen, A. Zernecke, R. R. Koenen, and C. Weber, "Platelet microparticles: a transcellular delivery system for RANTES promoting monocyte recruitment on endothelium," Arteriosclerosis, Thrombosis, and Vascular Biology, vol. 25, no. 7, pp. 1512-1518, 2005.

[64] A. I. Vinik, T. Erbas, T. Sun Park, R. Nolan, and G. L. Pittenger, "Platelet dysfunction in type 2 diabetes," Diabetes Care, vol. 24, no. 8, pp. 1476-1485, 2001.

[65] P. M. W. Bath and R. J. Butterworth, "Platelet size: measurement, physiology and vascular disease," Blood Coagulation \& Fibrinolysis, vol. 7, no. 2, pp. 157-161, 1996.

[66] L. Vizioli, S. Muscari, and A. Muscari, "The relationship of mean platelet volume with the risk and prognosis of cardiovascular diseases," International Journal of Clinical Practice, vol. 63, no. 10, pp. 1509-1515, 2009.

[67] E. Coban, M. Ozdogan, G. Yazicioglu, and F. Akcit, "The mean platelet volume in patients with obesity," International Journal of Clinical Practice, vol. 59, no. 8, pp. 981-982, 2005.

[68] E. Coban, A. Yilmaz, and R. Sari, "The effect of weight loss on the mean platelet volume in obese patients," Platelets, vol. 18, no. 3, pp. 212-216, 2007.

[69] A. Muscari, S. De Pascalis, A. Cenni, C. Ludovico, N. Castaldini, S. Antonelli, G. Bianchi, D. Magalotti, and M. Zoli, "Determinants of mean platelet volume (MPV) in an elderly population: relevance of body fat, blood glucose and ischaemic electrocardiographic changes," Thrombosis and Haemostasis, vol. 99, no. 6, pp. 1079-1084, 2008.

[70] C. B. Thompson, J. A. Jakubowski, P. G. Quinn, D. Deykin, and C. R. Valeri, "Platelet size and age determine platelet function independently," Blood, vol. 63, no. 6, pp. 1372-1375, 1984.

[71] J. F. Martin, T. Shaw, J. Heggie, and D. G. Penington, "Measurement of the density of human platelets and its relationship to volume," British Journal of Haematology, vol. 54, no. 3, pp. 337-352, 1983.

[72] A. S. Brown, Y. Hong, A. de Belder, H. Beacon, J. Beeso, R. Sherwood, M. Edmonds, J. F. Martin, and J. D. Erusalimsky, "Megakaryocyte ploidy and platelet changes in human diabetes and atherosclerosis," Arteriosclerosis, Thrombosis, and Vascular Biology, vol. 17, no. 4, pp. 802-807, 1997.

[73] H. Kimura, T. Ishibashi, Y. Shikama, et al., "Interleukin- $1 \beta$ (IL-1 $\beta$ ) induces thrombocytosis in mice: possible implication of IL-6," Blood, vol. 76, no. 12, pp. 2493-2500, 1990.

[74] E. Battinelli, S. R. Willoughby, T. Foxall, C. R. Valeri, and J. Loscalzo, "Induction of platelet formation from megakaryocytoid cells by nitric oxide," Proceedings of the National Academy of Sciences of the United States of America, vol. 98, no. 25, pp. 14458-14463, 2001.

[75] A. M. Lefer and X.-L. Ma, "Cytokines and growth factors in endothelial dysfunction," Critical Care Medicine, vol. 21, no. 2, pp. S9-S14, 1993.
[76] G. Davì, M. T. Guagnano, G. Ciabattoni, S. Basili, A. Falco, M. Marinopiccoli, M. Nutini, S. Sensi, and C. Patrono, "Platelet activation in obese women: role of inflammation and oxidant stress," Journal of the American Medical Association, vol. 288, no. 16, pp. 2008-2014, 2002.

[77] M. Trovati, G. Anfossi, F. Cavalot, P. Massucco, E. Mularoni, and G. Emanuelli, "Insulin directly reduces platelet sensitivity to aggregating agents. Studies in vitro and in vivo," Diabetes, vol. 37, no. 6, pp. 780-786, 1988.

[78] M. Trovati and G. Anfossi, "Influence of insulin and of insulin resistance on platelet and vascular smooth muscle cell function," Journal of Diabetes and Its Complications, vol. 16, no. 1, pp. 35-40, 2002.

[79] I. Russo, P. Massucco, L. Mattiello, F. Cavalot, G. Anfossi, and M. Trovati, "Comparison between the effects of the rapid recombinant insulin analog aspart and those of human regular insulin on platelet cyclic nucleotides and aggregation," Thrombosis Research, vol. 107, no. 1-2, pp. 31-37, 2002.

[80] K. Hiramatsu, H. Nozaki, and S. Arimori, "Reduction of platelet aggregation induced by euglycaemic insulin clamp," Diabetologia, vol. 30, no. 5, pp. 310-313, 1987.

[81] J. Westerbacka, H. Yki-Järvinen, A. Turpeinen, A. Rissanen, S. Vehkavaara, M. Syrjälä, and R. Lassila, "Inhibition of platelet-collagen interaction: an in vivo action of insulin abolished by insulin resistance in obesity," Arteriosclerosis, Thrombosis, and Vascular Biology, vol. 22, no. 1, pp. 167-172, 2002.

[82] M. Trovati, G. Anfossi, P. Massucco, L. Mattiello, C. Costamagna, V. Piretto, E. Mularoni, F. Cavalot, A. Bosia, and D. Ghigo, "Insulin stimulates nitric oxide synthesis in human platelets and, through nitric oxide, increases platelet concentrations of both guanosine-3',5'-cyclic monophosphate and adenosine-3',5'-cyclic monophosphate," Diabetes, vol. 46, no. 5, pp. 742-749, 1997.

[83] M. Trovati, E. M. Mularoni, S. Burzacca, M. C. Ponziani, P. Massucco, L. Mattiello, V. Piretto, F. Cavalot, and G. Anfossi, "Impaired insulin-induced platelet antiaggregating effect in obesity and in obese NIDDM patients," Diabetes, vol. 44, no. 11, pp. 1318-1322, 1995.

[84] M. Trovati and G. Anfossi, "Insulin, insulin resistance and platelet function: similarities with insulin effects on cultured vascular smooth muscle cells," Diabetologia, vol. 41, no. 6, pp. 609-622, 1998.

[85] I. A. Ferreira, A. I. M. Mocking, M. A. H. Feijge, G. Gorter, T. W. Van Haeften, J. W. M. Heemskerk, and J.-W. N. Akkerman, "Platelet inhibition by insulin is absent in type 2 diabetes mellitus," Arteriosclerosis, Thrombosis, and Vascular Biology, vol. 26, no. 2, pp. 417-422, 2006.

[86] G. Anfossi, I. Russo, P. Massucco, L. Mattiello, G. Doronzo, A. De Salve, and M. Trovati, "Impaired synthesis and action of antiaggregating cyclic nucleotides in platelets from obese subjects: possible role in platelet hyperactivation in obesity," European Journal of Clinical Investigation, vol. 34, no. 7, pp. 482-489, 2004.

[87] I. Russo, P. Del Mese, G. Doronzo, A. De Salve, M. Secchi, M. Trovati, and G. Anfossi, "Platelet resistance to the antiaggregatory cyclic nucleotides in central obesity involves reduced phosphorylation of vasodilator-stimulated phosphoprotein," Clinical Chemistry, vol. 53, no. 6, pp. 1053-1060, 2007.

[88] H. K. Vincent, K. E. Innes, and K. R. Vincent, "Oxidative stress and potential interventions to reduce oxidative stress in overweight and obesity," Diabetes, Obesity and Metabolism, vol. 9, no. 6, pp. 813-839, 2007. 
[89] S. Furukawa, T. Fujita, M. Shimabukuro, M. Iwaki, Y. Yamada, Y. Nakajima, O. Nakayama, M. Makishima, M. Matsuda, and I. Shimomura, "Increased oxidative stress in obesity and its impact on metabolic syndrome," Journal of Clinical Investigation, vol. 114, no. 12, pp. 1752-1761, 2004.

[90] M. Suematsu, A. Katsuki, Y. Sumida, E. C. Gabazza, S. Murashima, K. Matsumoto, N. Kitagawa, H. Akatsuka, Y. Hori, K. Nakatani, K. Togashi, Y. Yano, and Y. Adachi, "Decreased circulating levels of active ghrelin are associated with increased oxidative stress in obese subjects," European Journal of Endocrinology, vol. 153, no. 3, pp. 403-407, 2005.

[91] B. J. Goldstein, R. G. Scalia, and X. L. Ma, "Protective vascular and myocardial effects of adiponectin," Nature Clinical Practice Cardiovascular Medicine, vol. 6, no. 1, pp. 27-35, 2009.

[92] P. Pignatelli, F. M. Pulcinelli, L. Lenti, P. P. Gazzaniga, and F. Violi, "Hydrogen peroxide is involved in collagen-induced platelet activation," Blood, vol. 91, no. 2, pp. 484-490, 1998.

[93] F. M. Pulcinelli, P. Pignatelli, F. Violi, and P. P. Gazzaniga, "Platelets and oxygen radicals: mechanisms of functional modulation," Haematologica, vol. 86 , no. 11, supplement 2, pp. 31-34, 2001.

[94] A. J. Begonja, S. Gambaryan, J. R. Geiger, B. Aktas, M. Pozgajova, B. Nieswandt, and U. Walter, "Platelet NAD $(\mathrm{P}) \mathrm{H}$ oxidase-generated ROS production regulates $\alpha \operatorname{IIb} \beta 3$-integrin activation independent of the NO/cGMP pathway," Blood, vol. 106, no. 8, pp. 2757-2760, 2005.

[95] J. D. Morrow, K. E. Hill, R. F. Burk, T. M. Nammour, K. F. Badr, and L. J. Roberts II, "A series of prostaglandin F2-like compounds are produced in vivo in humans by a non-cyclooxygenase, free radical-catalyzed mechanism," Proceedings of the National Academy of Sciences of the United States of America, vol. 87, no. 23, pp. 9383-9387, 1990.

[96] G. L. Milne, H. Yin, and J. D. Morrow, "Human biochemistry of the isoprostane pathway," Journal of Biological Chemistry, vol. 283, no. 23, pp. 15533-15537, 2008.

[97] C. Patrono and G. A. FitzGerald, "Isoprostanes: potential markers of oxidant stress in atherothrombotic disease," Arteriosclerosis, Thrombosis, and Vascular Biology, vol. 17, no. 11, pp. 2309-2315, 1997.

[98] L. J. Roberts II and J. D. Morrow, "Measurement of $F_{2}$ isoprostanes as an index of oxidative stress in vivo," Free Radical Biology \& Medicine, vol. 28, no. 4, pp. 505-513, 2000.

[99] P. Montuschi, P. J. Barnes, and L. J. Roberts II, “Isoprostanes: markers and mediators of oxidative stress," FASEB Journal, vol. 18, no. 15, pp. 1791-1800, 2004.

[100] F. Cipollone, G. Ciabattoni, P. Patrignani, M. Pasquale, D. Di Gregorio, T. Bucciarelli, G. Dav', F. Cuccurullo, and C. Patrono, "Oxidant stress and aspirin-insensitive thromboxane biosynthesis in severe unstable angina," Circulation, vol. 102, no. 9, pp. 1007-1013, 2000.

[101] D. Praticò, E. M. Smyth, F. Violi, and G. A. FitzGerald, "Local amplification of platelet function by 8 -epi prostaglandin F2 $\alpha$ is not mediated by thromboxane receptor isoforms," Journal of Biological Chemistry, vol. 271, no. 25, pp. 14916-14924, 1996.

[102] F. T. Khasawneh, J.-S. Huang, F. Mir, S. Srinivasan, C. Tiruppathi, and G. C. Le Breton, "Characterization of isoprostane signaling: evidence for a unique coordination profile of 8 -iso-PGF $2 \alpha$ with the thromboxane $\mathrm{A}_{2}$ receptor, and activation of a separate cAMP-dependent inhibitory pathway in human platelets," Biochemical Pharmacology, vol. 75, no. 12, pp. 2301-2315, 2008.
[103] L. P. Audoly, B. Rocca, J.-E. Fabre, B. H. Koller, D. Thomas, A. L. Loeb, T. M. Coffman, and G. A. FitzGerald, "Cardiovascular responses to the isoprostanes iPF2 $(\alpha)$-III and iPE2III are mediated via the thromboxane $\mathrm{A}_{2}$ receptor in vivo," Circulation, vol. 101, no. 24, pp. 2833-2840, 2000.

[104] G. Davì, P. Gresele, F. Violi, S. Basili, M. Catalano, C. Giammarresi, R. Volpato, G. G. Nenci, G. Ciabattoni, and C. Patrono, "Diabetes mellitus, hypercholesterolemia, and hypertension but not vascular disease per se are associated with persistent platelet activation in vivo: evidence derived from the study of peripheral arterial disease," Circulation, vol. 96, no. 1, pp. 69-75, 1997.

[105] J. F. Keaney Jr., M. G. Larson, R. S. Vasan, P. W. F. Wilson, I. Lipinska, D. Corey, J. M. Massaro, P. Sutherland, J. A. Vita, and E. J. Benjamin, "Obesity and systemic oxidative stress: clinical correlates of oxidative stress in the Framingham study," Arteriosclerosis, Thrombosis, and Vascular Biology, vol. 23, no. 3, pp. 434-439, 2003.

[106] K. Park, M. Gross, D.-H. Lee, P. Holvoet, J. H. Himes, J. M. Shikany, and D. R. Jacobs Jr., "Oxidative stress and insulin resistance: the coronary artery risk development in young adults study," Diabetes Care, vol. 32, no. 7, pp. 1302-1307, 2009.

[107] I.-J. Tsai, K. D. Croft, T. A. Mori, J. R. Falck, L. J. Beilin, I. B. Puddey, and A. E. Barden, "20-HETE and F2-isoprostanes in the metabolic syndrome: the effect of weight reduction," Free Radical Biology \& Medicine, vol. 46, no. 2, pp. 263-270, 2009.

[108] G. K. Owens, M. S. Kumar, and B. R. Wamhoff, "Molecular regulation of vascular smooth muscle cell differentiation in development and disease," Physiological Reviews, vol. 84, no. 3, pp. 767-801, 2004.

[109] T. Yoshida and G. K. Owens, "Molecular determinants of vascular smooth muscle cell diversity," Circulation Research, vol. 96, no. 3, pp. 280-291, 2005.

[110] S. Moncada and E. A. Higgs, "Nitric oxide and the vascular endothelium," Handbook of Experimental Pharmacology, no. 176, part 1, pp. 213-254, 2006.

[111] E. J. Tsai and D. A. Kass, "Cyclic GMP signaling in cardiovascular pathophysiology and therapeutics," Pharmacology of Therapeutics, vol. 122, no. 3, pp. 216-238, 2009.

[112] J. H. Lee and L. Ragolia, "AKT phosphorylation is essential for insulin-induced relaxation of rat vascular smooth muscle cells," American Journal of Physiology, vol. 291, no. 6, pp. C1355-C1365, 2006.

[113] B. C. Berk, "Vascular smooth muscle growth: autocrine growth mechanisms," Physiological Reviews, vol. 81, no. 3, pp. 999-1030, 2001.

[114] Z. M. Azar, M. Z. Mehdi, and A. K. Srivastava, "Insulin-like growth factor type-1 receptor transactivation in vasoactive peptide and oxidant-induced signaling pathways in vascular smooth muscle cells," Canadian Journal of Physiology and Pharmacology, vol. 85, no. 1, pp. 105-111, 2007.

[115] R. Muniyappa, M. Montagnani, K. K. Koh, and M. J. Quon, "Cardiovascular actions of insulin," Endocrine Reviews, vol. 28, no. 5, pp. 463-491, 2007.

[116] W. A. Hsueh and R. E. Law, "Insulin signaling in the arterial wall," American Journal of Cardiology, vol. 84, no. 1A, pp. 21J24J, 1999.

[117] C. C. Wang, I. Gurevich, and B. Draznin, "Insulin affects vascular smooth muscle cell phenotype and migration via distinct signaling pathways," Diabetes, vol. 52, no. 10, pp. 2562-2569, 2003.

[118] J. D. Peuler, S. M. Phare, A. R. Iannucci, and M. J. Hodorek, "Differential inhibitory effects of antidiabetic drugs on 
arterial smooth muscle cell proliferation," American Journal of Hypertension, vol. 9, no. 2, pp. 188-192, 1996.

[119] X.-P. Xi, K. Graf, S. Goetze, W. A. Hsueh, and R. E. Law, "Inhibition of MAP kinase blocks insulin-mediated DNA synthesis and transcriptional activation of c-fos by Elk-1 in vascular smooth muscle cells," FEBS Letters, vol. 417, no. 3, pp. 283-286, 1997.

[120] M. Cruzado, N. Risler, C. Castro, A. Ortiz, and M. E. Rüttler, "Proliferative effect of insulin on cultured smooth muscle cells from rat mesenteric resistance vessels," American Journal of Hypertension, vol. 11, no. 1, pp. 54-58, 1998.

[121] G. Doronzo, I. Russo, L. Mattiello, G. Anfossi, A. Bosia, and M. Trovati, "Insulin activates vascular endothelial growth factor in vascular smooth muscle cells: influence of nitric oxide and of insulin resistance," European Journal of Clinical Investigation, vol. 34, no. 10, pp. 664-673, 2004.

[122] G. Doronzo, I. Russo, L. Mattiello, C. Riganti, G. Anfossi, and M. Trovati, "Insulin activates hypoxia-inducible factor$1 \alpha$ in human and rat vascular smooth muscle cells via phosphatidylinositol-3 kinase and mitogen-activated protein kinase pathways: impairment in insulin resistance owing to defects in insulin signalling," Diabetologia, vol. 49, no. 5, pp. 1049-1063, 2006.

[123] R. Muniyappa and M. J. Quon, "Insulin action and insulin resistance in vascular endothelium," Current Opinion in Clinical Nutrition and Metabolic Care, vol. 10, no. 4, pp. 523530, 2007.

[124] C. W. Pugh and P. J. Ratcliffe, "Regulation of angiogenesis by hypoxia: role of the HIF system," Nature Medicine, vol. 9, no. 6, pp. 677-684, 2003.

[125] N. Ferrara and T. Davis-Smyth, "The biology of vascular endothelial growth factor," Endocrine Reviews, vol. 18, no. 1, pp. 4-25, 1997.

[126] E. W. Raines and R. Ross, "Smooth muscle cells and the pathogenesis of the lesions of atherosclerosis," British Heart Journal, vol. 69, no. 1, pp. S30-S37, 1993.

[127] R. Ross, "Cell biology of atherosclerosis," Annual Review of Physiology, vol. 57, pp. 791-804, 1995.

[128] A. C. Newby, "Matrix metalloproteinases regulate migration, proliferation, and death of vascular smooth muscle cells by degrading matrix and non-matrix substrates," Cardiovascular Research, vol. 69, no. 3, pp. 614-624, 2006.

[129] A. C. Newby, "Metalloproteinases and vulnerable atherosclerotic plaques," Trends in Cardiovascular Medicine, vol. 17, no. 8, pp. 253-258, 2007.

[130] J. L. Johnson, "Matrix metalloproteinases: influence on smooth muscle cells and atherosclerotic plaque stability," Expert Review of Cardiovascular Therapy, vol. 5, no. 2, pp. 265-282, 2007.

[131] A. Vink, A. H. Schoneveld, D. Lamers, A. J. S. Houben, P. van der Groep, P. J. van Diest, and G. Pasterkamp, "HIF-1alpha expression is associated with an atheromatous inflammatory plaque phenotype and upregulated in activated macrophages," Atherosclerosis, vol. 195, no. 2, pp. e69e75, 2007.

[132] J. C. Sluimer, J.-M. Gasc, J. L. van Wanroij, N. Kisters, M. Groeneweg, M. D. Sollewijn Gelpke, J. P. Cleutjens, L. H. van den Akker, P. Corvol, B. G. Wouters, M. J. Daemen, and A.-P. J. Bijnens, "Hypoxia, hypoxia-inducible transcription factor, and macrophages in human atherosclerotic plaques are correlated with intraplaque angiogenesis," Journal of the American College of Cardiology, vol. 51, no. 13, pp. 12581265, 2008.
[133] M. Osada-Oka, T. Ikeda, S. Imaoka, S. Akiba, and T. Sato, "VEGF-enhanced proliferation under hypoxia by an autocrine mechanism in human vascular smooth muscle cells," Journal of Atherosclerosis and Thrombosis, vol. 15, no. 1, pp. 26-33, 2008.

[134] P. W. Holm, R. H. J. A. Slart, C. J. Zeebregts, J. L. Hillebrands, and R. A. Tio, "Atherosclerotic plaque development and instability: a dual role for VEGF," Annals of Medicine, vol. 41, no. 4, pp. 257-264, 2009.

[135] C. D. Stiles, G. T. Capone, and C. D. Scher, "Dual control of cell growth by somatomedins and platelet-derived growth factor," Proceedings of the National Academy of Sciences of the United States of America, vol. 76, no. 3, pp. 1279-1283, 1979.

[136] E. W. Raines, "PDGF and cardiovascular disease," Cytokine and Growth Factor Reviews, vol. 15, no. 4, pp. 237-254, 2004.

[137] H. Yanagi, Y. Sasaguri, K. Sugama, M. Morimatsu, and H. Nagase, "Production of tissue collagenase (matrix metalloproteinase 1) by human aortic smooth muscle cells in response to platelet-derived growth factor," Atherosclerosis, vol. 91, no. 3, pp. 207-216, 1991.

[138] Z. S. Galis, M. Muszynski, G. K. Sukhova, E. SimonMorrissey, E. N. Unemori, M. W. Lark, E. Amento, and P. Libby, "Cytokine-stimulated human vascular smooth muscle cells synthesize a complement of enzymes required for extracellular matrix digestion," Circulation Research, vol. 75, no. 1, pp. 181-189, 1994.

[139] T. Sasaguri, N. Arima, A. Tanimoto, S. Shimajiri, T. Hamada, and Y. Sasaguri, "A role for interleukin 4 in production of matrix metalloproteinase 1 by human aortic smooth muscle cells," Atherosclerosis, vol. 138, no. 2, pp. 247-253, 1998.

[140] G. Doronzo, I. Russo, L. Mattiello, M. Trovati, and G. Anfossi, "C-reactive protein increases matrix metalloproteinase-2 expression and activity in cultured human vascular smooth muscle cells," Journal of Laboratory and Clinical Medicine, vol. 146, no. 5, pp. 287-298, 2005.

[141] J. D. Raffetto and R. A. Khalil, "Matrix metalloproteinases and their inhibitors in vascular remodeling and vascular disease," Biochemical Pharmacology, vol. 75, no. 2, pp. 346359, 2008.

[142] H. Chai, K. Aghaie, and W. Zhou, "Soluble CD40 ligand induces human coronary artery smooth muscle cells proliferation and migration," Surgery, vol. 146, no. 1, pp. 5-11, 2009.

[143] M. J. Davies, P. D. Richardson, N. Woolf, D. R. Katz, and J. Mann, "Risk of thrombosis in human atherosclerotic plaques: role of extracellular lipid, macrophage, and smooth muscle cell content," British Heart Journal, vol. 69, no. 5, pp. 377-381, 1993.

[144] P. L. Weissberg, G. J. Clesham, and M. R. Bennett, "Is vascular smooth muscle cell proliferation beneficial?" The Lancet, vol. 347, no. 8997, pp. 305-307, 1996.

[145] T. D. Littlewood and M. R. Bennett, "Apoptotic cell death in atherosclerosis," Current Opinion in Lipidology, vol. 14, no. 5, pp. 469-475, 2003.

[146] M. C. H. Clarke, N. Figg, J. J. Maguire, A. P. Davenport, M. Goddard, T. D. Littlewood, and M. R. Bennett, "Apoptosis of vascular smooth muscle cells induces features of plaque vulnerability in atherosclerosis," Nature Medicine, vol. 12, no. 9, pp. 1075-1080, 2006.

[147] E. Lutgens, E. D. de Muinck, P. J. E. H. M. Kitslaar, J. H. M. Tordoir, H. J. J. Wellens, and M. J. A. P. Daemen, "Biphasic pattern of cell turnover characterizes the progression from fatty streaks to ruptured human atherosclerotic plaques," Cardiovascular Research, vol. 41, no. 2, pp. 473-479, 1999. 
[148] F. J. Schaub, W. C. Liles, N. Ferri, K. Sayson, R. A. Seifert, and D. F. Bowen-Pope, "Fas and Fas-associated death domain protein regulate monocyte chemoattractant protein1 expression by human smooth muscle cells through caspaseand calpain-dependent release of interleukin-1 $\alpha$," Circulation Research, vol. 93, no. 6, pp. 515-522, 2003.

[149] F. J. Schaub, D. K. M. Han, W. C. Liles, L. D. Adams, S. A. Coats, R. K. Ramachandran, R. A. Seifert, S. M. Schwartz, and D. F. Bowen-Pope, "Fas/FADD-mediated activation of a specific program of inflammatory gene expression in vascular smooth muscle cells," Nature Medicine, vol. 6, no. 7, pp. 790796, 2000.

[150] P. D. Flynn, C. D. Byrne, T. P. Baglin, P. L. Weissberg, and M. R. Bennett, "Thrombin generation by apoptotic vascular smooth muscle cells," Blood, vol. 89, no. 12, pp. 4378-4384, 1997.

[151] D. Proudfoot, J. N. Skepper, L. Hegyi, M. R. Bennett, C. M. Shanahan, and P. L. Weissberg, "Apoptosis regulates human vascular calcification in vitro: evidence for initiation of vascular calcification by apoptotic bodies," Circulation Research, vol. 87, no. 11, pp. 1055-1062, 2000.

[152] Z. Mallat, B. Hugel, J. Ohan, G. Lesèche, J.-M. Freyssinet, and A. Tedgui, "Shed membrane microparticles with procoagulant potential in human atherosclerotic plaques: a role for apoptosis in plaque thrombogenicity," Circulation, vol. 99, no. 3, pp. 348-353, 1999.

[153] Z. Mallat, H. Benamer, B. Hugel, J. Benessiano, P. G. Steg, J.-M. Freyssinet, and A. Tedgui, "Elevated levels of shed membrane microparticles with procoagulant potential in the peripheral circulating blood of patients with acute coronary syndromes," Circulation, vol. 101, no. 8, pp. 841-843, 2000.

[154] A. D. Schecter, B. Spirn, M. Rossikhina, P. L. A. Giesen, V. Bogdanov, J. T. Fallon, E. A. Fisher, L. M. Schnapp, Y. Nemerson, and M. B. Taubman, "Release of active tissue factor by human arterial smooth muscle cells," Circulation Research, vol. 87, no. 2, pp. 126-132, 2000.

[155] F. Gizard, C. Amant, O. Barbier, S. Bellosta, R. Robillard, F. Percevault, H. Sevestre, P. Krimpenfort, A. Corsini, J. Rochette, C. Glineur, J.-C. Fruchart, G. Torpier, and B. Staels, "PPARa inhibits vascular smooth muscle cell proliferation underlying intimal hyperplasia by inducing the tumor suppressor p16INK4a," Journal of Clinical Investigation, vol. 115, no. 11, pp. 3228-3238, 2005.

[156] F. Gizard, T. Nomiyama, Y. Zhao, H. M. Findeisen, E. B. Heywood, K. L. Jones, B. Staels, and D. Bruemmer, "The PPAR $\alpha /$ p16INK4a pathway inhibits vascular smooth muscle cell proliferation by repressing cell cycle-dependent telomerase activation," Circulation Research, vol. 103, no. 10, pp. 1155-1163, 2008.

[157] F. Gizard and D. Bruemmer, "Transcriptional control of vascular smooth muscle cell proliferation by peroxisome proliferator-activated receptor- $\gamma$ : therapeutic implications for cardiovascular diseases," PPAR Research, vol. 2008, Article ID 429123, 11 pages, 2008.

[158] B. Erdös, A. W. Miller, and D. W. Busija, "Impaired endothelium-mediated relaxation in isolated cerebral arteries from insulin-resistant rats," American Journal of Physiology, vol. 282, no. 6, pp. H2060-H2065, 2002.

[159] J. C. Frisbee and D. W. Stepp, "Impaired NO-dependent dilation of skeletal muscle arterioles in hypertensive diabetic obese Zucker rats," American Journal of Physiology, vol. 281, no. 3, pp. H1304-H1311, 2001.

[160] B. Erdös, J. A. Snipes, A. W. Miller, and D. W. Busija, "Cerebrovascular dysfunction in Zucker obese rats is mediated by oxidative stress and protein kinase C," Diabetes, vol. 53, no. 5, pp. 1352-1359, 2004.

[161] S. A. Cooper, A. Whaley-Connell, J. Habibi, Y. Wei, G. Lastra, C. Manrique, S. Stas, and J. R. Sowers, "Renin-angiotensinaldosterone system and oxidative stress in cardiovascular insulin resistance," American Journal of Physiology, vol. 293, no. 4, pp. H2009-H2023, 2007.

[162] C. Rask-Madsen and G. L. King, "Mechanisms of disease: endothelial dysfunction in insulin resistance and diabetes," Nature Clinical Practice Endocrinology \& Metabolism, vol. 3, no. 1, pp. 46-56, 2007.

[163] J. S. Beckman and W. H. Koppenol, "Nitric oxide, superoxide, and peroxynitrite: the good, the bad, and the ugly," American Journal of Physiology, vol. 271, no. 5, part 1, pp. C1424C1437, 1996.

[164] Z. Bagi, "Mechanisms of coronary microvascular adaptation to obesity," American Journal of Physiology, vol. 297, no. 3, pp. R556-R567, 2009.

[165] A. D. Baron, "Insulin resistance and vascular function," Journal of Diabetes and its Complications, vol. 16, no. 1, pp. 92-102, 2002.

[166] P. Dandona, A. Aljada, A. Chaudhuri, P. Mohanty, and R. Garg, "Metabolic syndrome: a comprehensive perspective based on interactions between obesity, diabetes, and inflammation," Circulation, vol. 111, no. 11, pp. 1448-1454, 2005.

[167] F. L. Marasciulo, M. Montagnani, and M. A. Potenza, "Endothelin-1: the Yin and Yang on vascular function," Current Medicinal Chemistry, vol. 13, no. 14, pp. 1655-1665, 2006.

[168] I. Russo, P. Del Mese, G. Doronzo, L. Mattiello, M. Viretto, A. Bosia, G. Anfossi, and M. Trovati, "Resistance to the nitric oxide/cyclic guanosine 5'-monophosphate/protein kinase G pathway in vascular smooth muscle cells from the obese zucker rat, a classical animal model of insulin resistance: role of oxidative stress," Endocrinology, vol. 149, no. 4, pp. 14801489, 2008.

[169] D. W. Laight, K. M. Kengatharan, N. K. Gopaul, E. E. Änggård, and M. J. Carrier, "Investigation of oxidant stress and vasodepression to glyceryl trinitrate in the obese Zucker rat in vivo," British Journal of Pharmacology, vol. 125, no. 4, pp. 895-901, 1998.

[170] L. A. Suzuki, M. Poot, R. G. Gerrity, and K. E. Bornfeldt, "Diabetes accelerates smooth muscle accumulation in lesions of atherosclerosis: lack of direct growth-promoting effects of high glucose levels," Diabetes, vol. 50, no. 4, pp. 851-860, 2001.

[171] P. S. Trivedi and L. A. Barouch, "Cardiomyocyte apoptosis in animal models of obesity," Current Hypertension Reports, vol. 10, no. 6, pp. 454-460, 2008.

[172] P. M. Absher, D. J. Schneider, L. C. Baldor, J. C. Russell, and B. E. Sobel, "The retardation of vasculopathy induced by attenuation of insulin resistance in the corpulent JCR:LA$\mathrm{cp}$ rat is reflected by decreased vascular smooth muscle cell proliferation in vivo," Atherosclerosis, vol. 143, no. 2, pp. 245251, 1999.

[173] C. V. Desouza, M. Gerety, and F. G. Hamel, "Neointimal hyperplasia and vascular endothelial growth factor expression are increased in normoglycemic, insulin resistant, obese fatty rats," Atherosclerosis, vol. 184, no. 2, pp. 283-289, 2006.

[174] J. Kim, R. A. Bachmann, and J. Chen, "Interleukin-6 and insulin resistance," Vitamins and Hormones, vol. 80, pp. 613633, 2009.

[175] R. Komowski, G. S. Mintz, K. M. Kent, A. D. Pichard, L. F. Satler, T. A. Bucher, M. K. Hong, J. J. Popma, and M. B. Leon, 
"Increased restenosis in diabetes mellitus after coronary interventions is due to exaggerated intimal hyperplasia: a serial intravascular ultrasound study," Circulation, vol. 95, no. 6, pp. 1366-1369, 1997.

[176] V. J. Dzau, R. C. Braun-Dullaeus, and D. G. Sedding, "Vascular proliferation and atherosclerosis: new perspectives and therapeutic strategies," Nature Medicine, vol. 8, no. 11, pp. 1249-1256, 2002.

[177] C. D. Protack, A. M. Bakken, J. Xu, W. A. Saad, A. B. Lumsden, and M. G. Davies, "Metabolic syndrome: a predictor of adverse outcomes after carotid revascularization," Journal of Vascular Surgery, vol. 49, no. 5, pp. 1172-1180, 2009.

[178] T. Takagi, T. Akasaka, A. Yamamuro, Y. Honda, T. Hozumi, S. Morioka, and K. Yoshida, "Impact of insulin resistance on neointimal tissue proliferation after coronary stent implantationIntravascular ultrasound studies," Journal of Diabetes and its Complications, vol. 16, no. 1, pp. 50-55, 2002.

[179] P. Piatti, C. Di Mario, L. D. Monti, G. Fragasso, F. Sgura, A. Caumo, E. Setola, P. Lucotti, E. Galluccio, C. Ronchi, A. Origgi, I. Zavaroni, A. Margonato, and A. Colombo, "Association of insulin resistance, hyperleptinemia and impaired nitric oxide release with in-stent restenosis in patients undergoing coronary stenting," Circulation, vol. 108, no. 17, pp. 2074-2081, 2003.

[180] A. Shah, N. Mehta, and M. P. Reilly, "Adipose inflammation, insulin resistance, and cardiovascular disease," Journal of Parenteral and Enteral Nutrition, vol. 32, no. 6, pp. 638-644, 2008.

[181] G. Fantuzzi and R. Faggioni, "Leptin in the regulation of immunity, inflammation, and hematopoiesis," Journal of Leukocyte Biology, vol. 68, no. 4, pp. 437-446, 2000.

[182] M. Y. Abeywardena, W. R. Leifert, K. E. Warnes, J. N. Varghese, and R. J. Head, "Cardiovascular biology of interleukin6," Current Pharmaceutical Design, vol. 15, no. 15, pp. 18091821, 2009.

[183] H. Schuett, M. Luchtefeld, C. Grothusen, K. Grote, and B. Schieffer, "How much is too much? Interleukin-6 and its signalling in atherosclerosis," Thrombosis and Haemostasis, vol. 102, no. 2, pp. 215-222, 2009.

[184] J. S. Yudkin, M. Kumari, S. E. Humphries, and V. MohamedAli, "Inflammation, obesity, stress and coronary heart disease: is interleukin-6 the link?" Atherosclerosis, vol. 148, no. 2, pp. 209-214, 2000.

[185] Z. Wang, M. R. Castresana, and W. H. Newman, "Reactive oxygen and NF- $\kappa \mathrm{B}$ in VEGF-induced migration of human vascular smooth muscle cells," Biochemical and Biophysical Research Communications, vol. 285, no. 3, pp. 669-674, 2001.

[186] M. M. Hartge, T. Unger, and U. Kintscher, "The endothelium and vascular inflammation in diabetes," Diabetes and Vascular Disease Research, vol. 4, no. 2, pp. 84-88, 2007.

[187] R. E. Lamb and B. J. Goldstein, "Modulating an oxidativeinflammatory cascade: potential new treatment strategy for improving glucose metabolism, insulin resistance, and vascular function," International Journal of Clinical Practice, vol. 62, no. 7, pp. 1087-1095, 2008.

[188] E. Bruno and R. Hoffman, "Effect of interleukin 6 on in vitro human megakaryocytopoiesis: its interaction with other cytokines," Experimental Hematology, vol. 17, no. 10, pp. 1038-1043, 1989.

[189] S. Baatout, "Interleukin-6 and megakaryocytopoiesis: an update," Annals of Hematology, vol. 73, no. 4, pp. 157-162, 1996.

[190] J. L. Williams, G. G. Pipia, N. S. Datta, and M. W. Long, "Thrombopoietin requires additional megakaryocyte-active cytokines for optimal ex vivo expansion of megakaryocyte precursor cells," Blood, vol. 91, no. 11, pp. 4118-4126, 1998.

[191] L. Lazzari, R. Henschler, L. Lecchi, P. Rebulla, R. Mertelsmann, and G. Sirchia, "Interleukin-6 and interleukin-11 act synergistically with thrombopoietin and stem cell factor to modulate ex vivo expansion of human $\mathrm{CD} 41^{+}$and $\mathrm{CD} 61^{+}$ megakaryocytic cells," Haematologica, vol. 85, no. 1, pp. 2530, 2000.

[192] R. Kurzrock, "Thrombopoietic factors in chronic bone marrow failure states: the platelet problem revisited," Clinical Cancer Research, vol. 11, no. 4, pp. 1361-1367, 2005.

[193] D. Samocha-Bonet, D. Justo, O. Rogowski, N. Saar, S. AbuAbeid, G. Shenkerman, I. Shapira, S. Berliner, and A. Tomer, "Platelet counts and platelet activation markers in obese subjects," Mediators of Inflammation, vol. 2008, Article ID 834153, 6 pages, 2008.

[194] H. Q. Ly, A. J. Kirtane, S. A. Murphy, J. Buros, C. P. Cannon, E. Braunwald, and C. M. Gibson, "Association of platelet counts on presentation of clinical outcomes in ST-elevation myocardial infarction (from the TIMI Trials)," American Journal of Cardiology, vol. 98, no. 1, pp. 1-5, 2006.

[195] R. Kerr, D. Stirling, and C. A. Ludlam, "Interleukin 6 and haemostasis," British Journal of Haematology, vol. 115, no. 1, pp. 3-12, 2001.

[196] Y. Fan, J. Ye, F. Shen, Y. Zhu, Y. Yeghiazarians, W. Zhu, Y. Chen, M. T. Lawton, W. L. Young, and G.-Y. Yang, "Interleukin-6 stimulates circulating blood-derived endothelial progenitor cell angiogenesis in vitro," Journal of Cerebral Blood Flow and Metabolism, vol. 28, no. 1, pp. 90-98, 2008.

[197] R. Kranzhöfer, J. Schmidt, C. A. H. Pfeiffer, S. Hagl, P. Libby, and W. Kübler, "Angiotensin induces inflammatory activation of human vascular smooth muscle cells," Arteriosclerosis, Thrombosis, and Vascular Biology, vol. 19, no. 7, pp. 1623$1629,1999$.

[198] Z. Wang, M. R. Castresana, K. Detmer, and W. H. Newman, "An I $\kappa \mathrm{B}-\alpha$ mutant inhibits cytokine gene expression and proliferation in human vascular smooth muscle cells," Journal of Surgical Research, vol. 102, no. 2, pp. 198-206, 2002.

[199] Z. Wang, M. R. Castresana, and W. H. Newman, "NF- $\kappa$ B is required for TNF- $\alpha$-directed smooth muscle cell migration," FEBS Letters, vol. 508, no. 3, pp. 360-364, 2001.

[200] D. Wang, Z. Liu, Q. Li, M. Karpurapu, V. KundumaniSridharan, H. Cao, N. Dronadula, F. Rizvi, A. K. Bajpai, C. Zhang, G. Müller-Newen, K. W. Harris, and G. N. Rao, "An essential role for gp130 in neointima formation following arterial injury," Circulation Research, vol. 100, no. 6, pp. 807816, 2007.

[201] U. Ikeda, M. Ikeda, T. Oohara, A. Oguchi, T. Kamitani, Y. Tsuruya, and S. Kano, "Interleukin 6 stimulates growth of vascular smooth muscle cells in a PDGF-dependent manner," American Journal of Physiology, vol. 260, no. 5, pp. H1713H1717, 1991.

[202] T. Nabata, S. Morimoto, E. Koh, T. Shiraishi, and T. Ogihara, "Interleukin-6 stimulates c-myc expression and proliferation of cultured vascular smooth muscle cells," Biochemistry International, vol. 20, no. 3, pp. 445-454, 1990.

[203] Y. Hojo, U. Ikeda, T. Katsuki, O. Mizuno, H. Fukazawa, K. Kurosaki, H. Fujikawa, and K. Shimada, "Interleukin 6 expression in coronary circulation after coronary angioplasty as a risk factor for restenosis," Heart, vol. 84, no. 1, pp. 83-87, 2000.

[204] R. Sukhija, I. Fahdi, L. Garza, L. Fink, M. Scott, W. Aude, R. Pacheco, Z. Bursac, A. Grant, and J. L. Mehta, "Inflammatory Markers, Angiographic Severity of Coronary Artery Disease, 
and Patient Outcome," American Journal of Cardiology, vol. 99, no. 7, pp. 879-884, 2007.

[205] S. J. C. Warner and P. Libby, "Human vascular smooth muscle cells. Target for and source of tumor necrosis factor," Journal of Immunology, vol. 142, no. 1, pp. 100-109, 1989.

[206] P. Barath, M. C. Fishbein, J. Cao, J. Berenson, R. H. Helfant, and J. S. Forrester, "Detection and localization of tumor necrosis factor in human atheroma," American Journal of Cardiology, vol. 65, no. 5, pp. 297-302, 1990.

[207] S. Galic, J.S. Oakhill, and G.R. Steinberg, "Adipose tissue as an endocrine organ," Molecular and Cellular Endocrinology, vol. 316, no. 2, pp. 129-139, 2010.

[208] I. Nieto-Vazquez, S. Fernández-Veledo, D. K. Krämer, R. Vila-Bedmar, L. Garcia-Guerra, and M. Lorenzo, "Insulin resistance associated to obesity: the link TNF-alpha," Archives of Physiology and Biochemistry, vol. 114, no. 3, pp. 183-194, 2008.

[209] G. S. Hotamisligil, P. Arner, J. F. Caro, R. L. Atkinson, and B. M. Spiegelman, "Increased adipose tissue expression of tumor necrosis factor- $\alpha$ in human obesity and insulin resistance," Journal of Clinical Investigation, vol. 95, no. 5, pp. 2409-2415, 1995.

[210] J. Nilsson, S. Jovinge, A. Niemann, R. Reneland, and H. Lithell, "Relation between plasma tumor necrosis factora and insulin sensitivity in elderly men with non-insulindependent diabetes mellitus," Arteriosclerosis, Thrombosis, and Vascular Biology, vol. 18, no. 8, pp. 1199-1202, 1998.

[211] Y. Miyazaki, R. Pipek, L. J. Mandarino, and R. A. DeFronzo, "Tumor necrosis factor a and insulin resistance in obese type 2 diabetic patients," International Journal of Obesity, vol. 27, no. 1, pp. 88-94, 2003.

[212] C. Rask-Madsen, H. Domínguez, N. Ihlemann, T. Hermann, L. Køber, and C. Torp-Pedersen, "Tumor necrosis factor- $\alpha$ inhibits insulin's stimulating effect on glucose uptake and endothelium-dependent vasodilation in humans," Circulation, vol. 108, no. 15, pp. 1815-1821, 2003.

[213] J. M. Youd, S. Rattigan, and M. G. Clark, "Acute impairment of insulin-mediated capillary recruitment and glucose uptake rat skeletal muscle vivo by TNF- $\alpha$," Diabetes, vol. 49 , no. 11 , pp. 1904-1909, 2000.

[214] A. Aljada, H. Ghanim, E. Assian, and P. Dandona, "Tumor necrosis factor- $\alpha$ inhibits insulin-induced increase in endothelial nitric oxide synthase and reduces insulin receptor content and phosphorylation in human aortic endothelial cells," Metabolism, vol. 51, no. 4, pp. 487-491, 2002.

[215] E. C. Eringa, C. D. A. Stehouwer, K. Walburg, A. D. Clark, G. P. Van Nieuw Amerongen, N. Westerhof, and P. Sipkema, "Physiological concentrations of insulin induce endothelin-dependent vasoconstriction of skeletal muscle resistance arteries in the presence of tumor necrosis factora dependence on c-Jun N-terminal kinase," Arteriosclerosis, Thrombosis, and Vascular Biology, vol. 26, no. 2, pp. 274-280, 2006.

[216] F. M. A. C. Martens, T. J. Rabelink, J. Op 't Roodt, E. J. P. De Koning, and F. L. J. Visseren, "TNF- $\alpha$ induces endothelial dysfunction in diabetic adults, an effect reversible by the PPAR- $\gamma$ agonist pioglitazone," European Heart Journal, vol. 27, no. 13, pp. 1605-1609, 2006.

[217] D. B. Landry, L. L. Couper, S. R. Bryant, and V. Lindner, "Activation of the NF- $\kappa$ B and I $\kappa$ B system in smooth muscle cells after rat arterial injury: induction of vascular cell adhesion molecule-1 and monocyte chemoattractant protein-1," American Journal of Pathology, vol. 151, no. 4, pp. 1085-1095, 1997.
[218] T. Skoog, W. Dichtl, S. Boquist, C. Skoglund-Andersson, F. Karpe, R. Tang, M. G. Bond, U. De Faire, J. Nilsson, P. Eriksson, and A. Hamsten, "Plasma tumour necrosis factor$\alpha$ and early carotid atherosclerosis in healthy middle-aged men," European Heart Journal, vol. 23, no. 5, pp. 376-383, 2002.

[219] P. M. Ridker, N. Rifai, M. Pfeffer, F. Sacks, S. Lepage, and E. Braunwald, "Elevation of tumor necrosis factor- $\alpha$ and increased risk of recurrent coronary events after myocardial infarction," Circulation, vol. 101, no. 18, pp. 2149-2153, 2000.

[220] J. Bar, A. Zosmer, M. Hod, M. G. Elder, and M. H. F. Sullivan, "The regulation of platelet aggregation in vitro by interleukin- $1 \beta$ and tumor necrosis factor- $\alpha$ : changes in pregnancy and in pre-eclampsia," Thrombosis and Haemostasis, vol. 78, no. 4, pp. 1255-1261, 1997.

[221] L. De Biase, P. Pignatelli, L. Lenti, G. Tocci, F. Piccioni, S. Riondino, F. M. Pulcinelli, S. Rubattu, M. Volpe, and F. Violi, "Enhanced TNFa and oxidative stress in patients with heart failure: effect of TNFa on platelet $\mathrm{O}_{2}$-production," Thrombosis and Haemostasis, vol. 90, no. 2, pp. 317-325, 2003.

[222] P. Pignatelli, L. De Biase, L. Lenti, G. Tocci, A. Brunelli, R. Cangemi, S. Riondino, S. Grego, M. Volpe, and F. Violi, "Tumor necrosis factor- $\alpha$ as trigger of platelet activation in patients with heart failure," Blood, vol. 106, no. 6, pp. 19921994, 2005.

[223] P. F. Bodary, "Links between adipose tissue and thrombosis in the mouse," Arteriosclerosis, Thrombosis, and Vascular Biology, vol. 27, no. 11, pp. 2284-2291, 2007.

[224] S. B. Ng, Y. H. Tan, and G. R. Guy, "Differential induction of the interleukin- 6 gene by tumor necrosis factor and interleukin-1," Journal of Biological Chemistry, vol. 269, no. 29, pp. 19021-19027, 1994.

[225] R. V. Considine, M. K. Sinha, M. L. Heiman, A. Kriauciunas, T. W. Stephens, M. R. Nyce, J. P. Ohannesian, C. C. Marco, L. J. Mckee, T. L. Bauer, and J. F. Caro, "Serum immunoreactiveleptin concentrations in normal-weight and obese humans," The New England Journal of Medicine, vol. 334, no. 5, pp. 292295, 1996.

[226] L. A. Campfield, F. J. Smith, Y. Guisez, R. Devos, and P. Burn, "Recombinant mouse OB protein: evidence for a peripheral signal linking adiposity and central neural networks," Science, vol. 269, no. 5223, pp. 546-549, 1995.

[227] S. B. Heymsfield, A. S. Greenberg, K. Fujioka, R. M. Dixon, R. Kushner, T. Hunt, J. A. Lubina, J. Patane, B. Self, P. Hunt, and M. McCamish, "Recombinant leptin for weight loss in obese and lean adults: a randomized, controlled, dose-escalation trial," Journal of the American Medical Association, vol. 282, no. 16, pp. 1568-1575, 1999.

[228] J. Bełtowski, G. Wójcicka, and A. Jamroz, "Leptin decreases plasma paraoxonase 1 (PON1) activity and induces oxidative stress: the possible novel mechanism for proatherogenic effect of chronic hyperleptinemia," Atherosclerosis, vol. 170, no. 1, pp. 21-29, 2003.

[229] P. F. Bodary, S. Gu, Y. Shen, A. H. Hasty, J. M. Buckler, and D. T. Eitzman, "Recombinant leptin promotes atherosclerosis and thrombosis in apolipoprotein E-deficient mice," Arteriosclerosis, Thrombosis, and Vascular Biology, vol. 25, no. 8, pp. e119-e122, 2005.

[230] A. H. Hasty, H. Shimano, J.-I. Osuga, I. Namatame, A. Takahashi, N. Yahagi, S. Perrey, Y. Iizuka, Y. Tamura, M. Amemiya-Kudo, T. Yoshikawa, H. Okazaki, K. Ohashi, K. 
Harada, T. Matsuzaka, H. Sone, T. Gotoda, R. Nagai, S. Ishibashi, and N. Yamada, "Severe hypercholesterolemia, hypertriglyceridemia, and atherosclerosis in mice lacking both leptin and the low density lipoprotein receptor," Journal of Biological Chemistry, vol. 276, no. 40, pp. 37402-37408, 2001.

[231] S. S. Martin, A. Qasim, and M. P. Reilly, "Leptin resistance: a possible interface of inflammation and metabolism in obesity-related cardiovascular disease," Journal of the American College of Cardiology, vol. 52, no. 15, pp. 1201-1210, 2008.

[232] A. M. Wallace, A. D. McMahon, C. J. Packard, A. Kelly, J. Shepherd, A. Gaw, and N. Sattar, "Plasma leptin and the risk of cardiovascular disease in the west of Scotland coronary prevention study (WOSCOPS)," Circulation, vol. 104, no. 25, pp. 3052-3056, 2001.

[233] J. Gómez-Ambrosi, J. Salvador, C. Silva, C. Pastor, F. Rotellar, M. J. Gil, J. A. Cienfuegos, and G. Frühbeck, "Increased cardiovascular risk markers in obesity are associated with body adiposity: role of leptin," Thrombosis and Haemostasis, vol. 95, no. 6, pp. 991-996, 2006.

[234] W. Lieb, L. M. Sullivan, T. B. Harris, R. Roubenoff, E. Benjamin, D. Levy, C. S. Fox, T. J. Wang, P. W. Wilson, W. B. Kannel, and R. S. Vasan, "Plasma leptin levels and incidence of heart failure, cardiovascular disease, and total mortality in elderly individuals," Diabetes Care, vol. 32, no. 4, pp. 612616, 2009.

[235] G. Frühbeck, "Nutrition society medal lecture: a heliocentric view of leptin," Proceedings of the Nutrition Society, vol. 60, no. 3, pp. 301-318, 2001.

[236] S. Söderberg, B. Stegmayr, C. Ahlbeck-Glader, L. SlungaBirgander, B. Ahrén, and T. Olsson, "High leptin levels are associated with stroke," Cerebrovascular Diseases, vol. 15, no. 1-2, pp. 63-69, 2003.

[237] R. Wolk, P. Berger, R. J. Lennon, E. S. Brilakis, B. D. Johnson, and V. K. Somers, "Plasma leptin and prognosis in patients with established coronary atherosclerosis," Journal of the American College of Cardiology, vol. 44, no. 9, pp. 1819-1824, 2004.

[238] M. P. Reilly, N. Iqbal, M. Schutta, M. L. Wolfe, M. Scally, A. R. Localio, D. J. Rader, and S. E. Kimmel, "Plasma leptin levels are associated with coronary atherosclerosis in type 2 diabetes," Journal of Clinical Endocrinology and Metabolism, vol. 89, no. 8, pp. 3872-3878, 2004.

[239] A. Qasim, N. N. Mehta, M. G. Tadesse, M. L. Wolfe, T. Rhodes, C. Girman, and M. P. Reilly, "Adipokines, insulin resistance, and coronary artery calcification," Journal of the American College of Cardiology, vol. 52, no. 3, pp. 231-236, 2008.

[240] P. M. Piatti and L. D. Monti, "Insulin resistance, hyperleptinemia and endothelial dysfunction in coronary restenosis," Current Opinion in Pharmacology, vol. 5, no. 2, pp. 160164, 2005.

[241] M. Nakata, T. Yada, N. Soejima, and I. Maruyama, "Leptin promotes aggregation of human platelets via the long form of its receptor," Diabetes, vol. 48, no. 2, pp. 426-429, 1999.

[242] S. Konstantinides, K. Schäfer, S. Koschnick, and D. J. Loskutoff, "Leptin-dependent platelet aggregation and arterial thrombosis suggests a mechanism for atherothrombotic disease in obesity," Journal of Clinical Investigation, vol. 108, no. 10, pp. 1533-1540, 2001.

[243] A. Corsonello, F. Perticone, A. Malara, D. De Domenico, S. Loddo, M. Buemi, R. Ientile, and F. Corica,
"Leptin-dependent platelet aggregation in healthy, overweight and obese subjects," International Journal of Obesity, vol. 27, no. 5, pp. 566-573, 2003.

[244] H. S. Elbatarny and D. H. Maurice, "Leptin-mediated activation of human platelets: involvement of a leptin receptor and phosphodiesterase 3A-containing cellular signaling complex," American Journal of Physiology, vol. 289, no. 4, pp. E695-E702, 2005.

[245] S. Konstantinides, K. Schäfer, and D. J. Loskutoff, "The prothrombotic effects of leptin: possible implications for the risk of cardiovascular disease in obesity," Annals of the New York Academy of Sciences, vol. 947, pp. 134-142, 2001.

[246] F. Corica, A. Corsonello, M. Lucchetti, A. Malara, D. D. Domenico, L. Cannavò, S. Foti, A. Valenti, R. Ientile, and A. Saitta, "Relationship between metabolic syndrome and platelet responsiveness to leptin in overweight and obese patients," International Journal of Obesity, vol. 31, no. 5, pp. 842-849, 2007.

[247] C. Dellas, K. Schäfer, I. Rohm, M. Lankeit, T. Ellrott, V. Faustin, J. Riggert, G. Hasenfuss, and S. Konstantinides, "Absence of leptin resistance in platelets from morbidly obese individuals may contribute to the increased thrombosis risk in obesity," Thrombosis and Haemostasis, vol. 100, no. 6, pp. 1123-1129, 2008.

[248] B. Canavan, R. O. Salem, S. Schurgin, P. Koutkia, I. Lipinska, M. Laposata, and S. Grinspoon, "Effects of physiological leptin administration on markers of inflammation, platelet activation, and platelet aggregation during caloric deprivation," Journal of Clinical Endocrinology and Metabolism, vol. 90, no. 10, pp. 5779-5785, 2005.

[249] A. Corsonello and F. Corica, "Leptin, obesity and platelet responsiveness: another piece in the puzzle," Thrombosis and Haemostasis, vol. 100, no. 6, pp. 960-961, 2008.

[250] K. Rahmouni, D. A. Morgan, G. M. Morgan, A. L. Mark, and W. G. Haynes, "Role of selective leptin resistance in dietinduced obesity hypertension," Diabetes, vol. 54, no. 7, pp. 2012-2018, 2005.

[251] P. Kougias, H. Chai, P. H. Lin, Q. Yao, A. B. Lumsden, and C. Chen, "Effects of adipocyte-derived cytokines on endothelial functions: implication of vascular disease," Journal of Surgical Research, vol. 126, no. 1, pp. 121-129, 2005.

[252] K. A. L. Darvall, R. C. Sam, S. H. Silverman, A. W. Bradbury, and D. J. Adam, "Obesity and Thrombosis," European Journal of Vascular and Endovascular Surgery, vol. 33, no. 2, pp. 223233, 2007.

[253] J. Beltowski, "Leptin and atherosclerosis," Atherosclerosis, vol. 189, no. 1, pp. 47-60, 2006.

[254] K. Nakagawa, Y. Higashi, S. Sasaki, T. Oshima, H. Matsuura, and K. Chayama, "Leptin causes vasodilation in humans," Hypertension Research, vol. 25, no. 2, pp. 161-165, 2002.

[255] K. Matsuda, H. Teragawa, Y. Fukuda, K. Nakagawa, Y. Higashi, and K. Chayama, "Leptin causes nitric-oxide independent coronary artery vasolidation in humans," Hypertension Research, vol. 26, no. 2, pp. 147-152, 2003.

[256] G. Frühbeck, "Pivotal role of nitric oxide in the control of blood pressure after leptin administration," Diabetes, vol. 48, no. 4, pp. 903-908, 1999.

[257] G. Lembo, C. Vecchione, L. Fratta, G. Marino, V. Trimarco, G. D'Amati, and B. Trimarco, "Leptin induces direct vasodilation through distinct endothelial mechanisms," Diabetes, vol. 49, no. 2, pp. 293-297, 2000.

[258] C. Vecchione, A. Aretini, A. Maffei, G. Marino, G. Selvetella, R. Poulet, V. Trimarco, G. Frati, and G. Lembo, "Cooperation 
between insulin and leptin in the modulation of vascular tone," Hypertension, vol. 42, no. 2, pp. 166-170, 2003.

[259] A. Oda, T. Taniguchi, and M. Yokoyama, "Leptin stimulates rat aortic smooth muscle cell proliferation and migration," Kobe Journal of Medical Sciences, vol. 47, no. 3, pp. 141-150, 2001.

[260] L. Li, J.-C. Mamputu, N. Wiernsperger, and G. Renier, "Signaling pathways involved in human vascular smooth muscle cell proliferation and matrix metalloproteinase-2 expression induced by leptin: inhibitory effect of metformin," Diabetes, vol. 54, no. 7, pp. 2227-2234, 2005.

[261] F. Parhami, Y. Tintut, A. Ballard, A. M. Fogelman, and L. L. Demer, "Leptin enhances the calcification of vascular cells artery wall as a target of leptin," Circulation Research, vol. 88, no. 9, pp. 954-960, 2001.

[262] S. J. Cleland, N. Sattar, J. R. Petrie, N. G. Forouhi, H. L. Elliott, and J. M. C. Connell, "Endothelial dysfunction as a possible link between C-reactive protein levels and cardiovascular disease," Clinical Science, vol. 98, no. 5, pp. 531-535, 2000.

[263] P. E. Scherer, S. Williams, M. Fogliano, G. Baldini, and H. F. Lodish, "A novel serum protein similar to C1q, produced exclusively in adipocytes," Journal of Biological Chemistry, vol. 270, no. 45, pp. 26746-26749, 1995.

[264] S. H. Han, M. J. Quon, J.-A. Kim, and K. K. Koh, "Adiponectin and cardiovascular disease: response to therapeutic interventions," Journal of the American College of Cardiology, vol. 49, no. 5, pp. 531-538, 2007.

[265] R. Piñeiro, M. J. Iglesias, R. Gallego, K. Raghay, S. Eiras, J. Rubio, C. Diéguez, O. Gualillo, J. R. González-Juanatey, and F. Lago, "Adiponectin is synthesized and secreted by human and murine cardiomyocytes," FEBS Letters, vol. 579, no. 23, pp. 5163-5169, 2005.

[266] P. J. Havel, "Control of energy homeostasis and insulin action by adipocyte hormones: leptin, acylation stimulating protein, and adiponectin," Current Opinion in Lipidology, vol. 13, no. 1, pp. 51-59, 2002.

[267] U. Meier and A. M. Gressner, "Endocrine regulation of energy metabolism: review of pathobiochemical and clinical chemical aspects of leptin, ghrelin, adiponectin, and resistin," Clinical Chemistry, vol. 50, no. 9, pp. 1511-1525, 2004.

[268] H. Chen, M. Montagnani, T. Funahashi, I. Shimomura, and M. J. Quon, "Adiponectin stimulates production of nitric oxide in vascular endothelial cells," Journal of Biological Chemistry, vol. 278, no. 45, pp. 45021-45026, 2003.

[269] G. R. Soodini and O. Hamdy, "Adiponectin and leptin in relation to insulin sensitivity," Metabolic Syndrome and Related Disorders, vol. 2, no. 2, pp. 114-123, 2004.

[270] D. J. Dyck, "Adipokines as regulators of muscle metabolism and insulin sensitivity," Applied Physiology, Nutrition, and Metabolism, vol. 34, no. 3, pp. 396-402, 2009.

[271] N. Ouchi, S. Kihara, Y. Arita, Y. Okamoto, K. Maeda, H. Kuriyama, K. Hotta, M. Nishida, M. Takahashi, M. Muraguchi, Y. Ohmoto, T. Nakamura, S. Yamashita, T. Funahashi, and Y. Matsuzawa, "Adiponectin, an adipocytederived plasma protein, inhibits endothelial NF- $\kappa$ B signaling through a cAMP-dependent pathway," Circulation, vol. 102, no. 11, pp. 1296-1301, 2000.

[272] N. Ouchi and K. Walsh, "Adiponectin as an antiinflammatory factor," Clinica Chimica Acta, vol. 380, no. 1-2, pp. 24-30, 2007.

[273] C. Kobashi, M. Urakaze, M. Kishida, E. Kibayashi, H. Kobayashi, S. Kihara, T. Funahashi, M. Takata, R. Temaru,
A. Sato, K. Yamazaki, N. Nakamura, and M. Kobayashi, "Adiponectin inhibits endothelial synthesis of interleukin-8," Circulation Research, vol. 97, no. 12, pp. 1245-1252, 2005.

[274] T. Pischon, C. J. Girman, G. S. Hotamisligil, N. Rifai, F. B. $\mathrm{Hu}$, and E. B. Rimm, "Plasma adiponectin levels and risk of myocardial infarction in men," Journal of the American Medical Association, vol. 291, no. 14, pp. 1730-1737, 2004.

[275] H. Kato, H. Kashiwagi, M. Shiraga, S. Tadokoro, T. Kamae, H. Ujiie, S. Honda, S. Miyata, Y. Ijiri, J. Yamamoto, N. Maeda, T. Funahashi, Y. Kurata, I. Shimomura, Y. Tomiyama, and Y. Kanakura, "Adiponectin acts as an endogenous antithrombotic factor," Arteriosclerosis, Thrombosis, and Vascular Biology, vol. 26, no. 1, pp. 224-230, 2006.

[276] H. S. Elbatarny, S. J. Netherton, J. D. Ovens, A. V. Ferguson, and D. H. Maurice, "Adiponectin, ghrelin, and leptin differentially influence human platelet and human vascular endothelial cell functions: implication in obesity-associated cardiovascular diseases," European Journal of Pharmacology, vol. 558, no. 1-3, pp. 7-13, 2007.

[277] K. Bhagat and P. Vallance, "Inflammatory cytokines impair endothelium-dependent dilatation in human veins in vivo," Circulation, vol. 96, no. 9, pp. 3042-3047, 1997.

[278] D. C. W. Lau, B. Dhillon, H. Yan, P. E. Szmitko, and S. Verma, "Adipokines: molecular links between obesity and atheroslcerosis," American Journal of Physiology, vol. 288, no. 5, pp. H2031-H2041, 2005.

[279] Y. Arita, S. Kihara, N. Ouchi, K. Maeda, H. Kuriyama, Y. Okamoto, M. Kumada, K. Hotta, M. Nishida, M. Takahashi, T. Nakamura, I. Shimomura, M. Muraguchi, Y. Ohmoto, T. Funahashi, and Y. Matsuzawa, "Adipocyte-derived plasma protein adiponectin acts as a platelet-derived growth factorBB-binding protein and regulates growth factor-induced common postreceptor signal in vascular smooth muscle cell," Circulation, vol. 105, no. 24, pp. 2893-2898, 2002.

[280] Y. Wang, K. S. L. Lam, J. Y. Xu, G. Lu, L. Y. Xu, G. J. S. Cooper, and A. Xu, "Adiponectin inhibits cell proliferation by interacting with several growth factors in an oligomerizationdependent manner," Journal of Biological Chemistry, vol. 280, no. 18, pp. 18341-18347, 2005.

[281] Y. Okamoto, Y. Arita, M. Nishida, M. Muraguchi, N. Ouchi, M. Takahashi, T. Igura, Y. Inui, S. Kihara, T. Nakamura, S. Yamashita, J. Miyagawa, T. Funahashi, and Y. Matsuzawa, “An adipocyte-derived plasma protein, adiponectin, adheres to injured vascular walls," Hormone and Metabolic Research, vol. 32, no. 2, pp. 47-50, 2000.

[282] M. Kumada, S. Kihara, N. Ouchi, H. Kobayashi, Y. Okamoto, K. Ohashi, K. Maeda, H. Nagaretani, K. Kishida, N. Maeda, A. Nagasawa, T. Funahashi, and Y. Matsuzawa, "Adiponectin specifically increased tissue inhibitor of metalloproteinase-1 through interleukin-10 expression in human macrophages," Circulation, vol. 109, no. 17, pp. 2046-2049, 2004.

[283] M. Kojima, H. Hosoda, Y. Date, M. Nakazato, H. Matsuo, and K. Kangawa, "Ghrelin is a growth-hormone-releasing acylated peptide from stomach," Nature, vol. 402, no. 6762, pp. 656-660, 1999.

[284] F. Broglio, F. Prodam, F. Riganti, G. Muccioli, and E. Ghigo, "Ghrelin: from somatotrope secretion to new perspectives in the regulation of peripheral metabolic functions," Frontiers of Hormone Research, vol. 35, pp. 102-114, 2006.

[285] M. Tschöp, C. Weyer, P. A. Tataranni, V. Devanarayan, E. Ravussin, and M. L. Heiman, "Circulating ghrelin levels are decreased in human obesity," Diabetes, vol. 50, no. 4, pp. 707709, 2001. 
[286] V. Sharma and J. H. McNeill, "The emerging roles of leptin and ghrelin in cardiovascular physiology and pathophysiology," Current Vascular Pharmacology, vol. 3, no. 2, pp. 169180, 2005.

[287] M. Tesauro, F. Schinzari, V. Rovella, N. Di Daniele, D. Lauro, N. Mores, A. Veneziani, and C. Cardillo, "Ghrelin restores the endothelin 1/nitric oxide balance in patients with obesityrelated metabolic syndrome," Hypertension, vol. 54, no. 5, pp. 995-1000, 2009.

[288] F. Rossi, A. Castelli, M. J. Bianco, C. Bertone, M. Brama, and V. Santiemma, "Ghrelin inhibits contraction and proliferation of human aortic smooth muscle cells by cAMP/PKA pathway activation," Atherosclerosis, vol. 203, no. 1, pp. 97$104,2009$.

[289] G.-Z. Li, W. Jiang, J. Zhao, C.-S. Pan, J. Cao, C.-S. Tang, and L. Chang, "Ghrelin blunted vascular calcification in vivo and in vitro in rats," Regulatory Peptides, vol. 129, no. 1-3, pp. 167-176, 2005.

[290] K. Tatemoto, M. Hosoya, Y. Habata, R. Fujii, T. Kakegawa, M.-X. Zou, Y. Kawamata, S. Fukusumi, S. Hinuma, C. Kitada, T. Kurokawa, H. Onda, and M. Fujino, "Isolation and characterization of a novel endogenous peptide ligand for the human APJ receptor," Biochemical and Biophysical Research Communications, vol. 251, no. 2, pp. 471-476, 1998.

[291] C. Carpéné, C. Dray, C. Attané, P. Valet, M. P. Portillo, I. Churruca, F. I. Milagro, and I. Castan-Laurell, "Expanding role for the apelin/APJ system in physiopathology," Journal of Physiology and Biochemistry, vol. 63, no. 4, pp. 359-374, 2007.

[292] J. Boucher, B. Masri, D. Daviaud, S. Gesta, C. Guigné, A. Mazzucotelli, I. Castan-Laurell, I. Tack, B. Knibiehler, C. Carpéné, Y. Audigier, J.-S. Saulnier-Blache, and P. Valet, "Apelin, a newly identified adipokine up-regulated by insulin and obesity," Endocrinology, vol. 146, no. 4, pp. 1764-1771, 2005.

[293] L. Wei, X. Hou, and K. Tatemoto, "Regulation of apelin mRNA expression by insulin and glucocorticoids in mouse 3T3-L1 adipocytes," Regulatory Peptides, vol. 132, no. 1-3, pp. 27-32, 2005.

[294] A. G. Japp, N. L. Cruden, D. A. B. Amer, V. K. Y. Li, E. B. Goudie, N. R. Johnston, S. Sharma, I. Neilson, D. J. Webb, I. L. Megson, A. D. Flapan, and D. E. Newby, "Vascular effects of apelin in vivo in man," Journal of the American College of Cardiology, vol. 52, no. 11, pp. 908-913, 2008.

[295] B. Chandrasekaran, O. Dar, and T. McDonagh, "The role of apelin in cardiovascular function and heart failure," European Journal of Heart Failure, vol. 10, no. 8, pp. 725-732, 2008.

[296] M. M. Chen, E. A. Ashley, D. X. F. Deng, A. Tsalenko, A. Deng, R. Tabibiazar, A. Ben-Dor, B. Fenster, E. Yang, J. Y. King, M. Fowler, R. Robbins, F. L. Johnson, L. Bruhn, T. McDonagh, H. Dargie, Z. Yakhini, P. S. Tsao, and T. Quertermous, "Novel role for the potent endogenous inotrope apelin in human cardiac dysfunction," Circulation, vol. 108, no. 12, pp. 1432-1439, 2003.

[297] N. J. Leeper, M. M. Tedesco, Y. Kojima, G. M. Schultz, R. K. Kundu, E. A. Ashley, P. S. Tsao, R. L. Dalman, and T. Quertermous, "Apelin prevents aortic aneurysm formation by inhibiting macrophage inflammation," American Journal of Physiology, vol. 296, no. 5, pp. H1329-H1335, 2009.

[298] J. Bełtowski, "Apelin and visfatin: unique "beneficial" adipokines upregulated in obesity?" Medical Science Monitor, vol. 12, no. 6, pp. RA112-RA119, 2006.

[299] T. Hashimoto, M. Kihara, N. Imai, S.-I. Yoshida, H. Shimoyamada, H. Yasuzaki, J. Ishida, Y. Toya, Y. Kiuchi, N. Hirawa,
K. Tamura, T. Yazawa, H. Kitamura, A. Fukamizu, and S. Umemura, "Requirement of apelin-apelin receptor system for oxidative stress-linked atherosclerosis," American Journal of Pathology, vol. 171, no. 5, pp. 1705-1712, 2007.

[300] B. Masri, N. Morin, M. Cornu, B. Knibiehler, and Y. Audigier, "Apelin (65-77) activates p70 S6 kinase and is mitogenic for umbilical endothelial cells," FASEB Journal, vol. 18, no. 15, pp. 1909-1911, 2004.

[301] M. J. Kleinz, J. N. Skepper, and A. P. Davenport, "Immunocytochemical localisation of the apelin receptor, APJ, to human cardiomyocytes, vascular smooth muscle and endothelial cells," Regulatory Peptides, vol. 126, no. 3, pp. 233-240, 2005.

[302] T. Hashimoto, M. Kihara, J. Ishida, N. Imai, S.-I. Yoshida, Y. Toya, A. Fukamizu, H. Kitamura, and S. Umemura, "Apelin stimulates myosin light chain phosphorylation in vascular smooth muscle cells," Arteriosclerosis, Thrombosis, and Vascular Biology, vol. 26, no. 6, pp. 1267-1272, 2006.

[303] F. Li, L. Li, X. Qin, W. Pan, F. Feng, F. Chen, B. Zhu, D. Liao, H. Tanowitz, C. Albanese, and L. Chen, "Apelin-induced vascular smooth muscle cell proliferation: the regulation of cyclin D1," Frontiers in Bioscience, vol. 13, no. 10, pp. 37863792, 2008.

[304] B. Samal, Y. Sun, G. Stearns, C. Xie, S. Suggs, and I. McNiece, "Cloning and characterization of the cDNA encoding a novel human pre-B-cell colony-enhancing factor," Molecular and Cellular Biology, vol. 14, no. 2, pp. 1431-1437, 1994.

[305] A. R. Moschen, A. Kaser, B. Enrich, B. Mosheimer, M. Theurl, H. Niederegger, and H. Tilg, "Visfatin, an adipocytokine with proinflammatory and immunomodulating properties," Journal of Immunology, vol. 178, no. 3, pp. 1748-1758, 2007.

[306] N. Rasouli and P. A. Kern, "Adipocytokines and the metabolic complications of obesity," Journal of Clinical Endocrinology and Metabolism, vol. 93, no. 11, pp. s64-s73, 2008.

[307] A. Garten, S. Petzold, A. Körner, S.-I. Imai, and W. Kiess, "Nampt: linking NAD biology, metabolism and cancer," Trends in Endocrinology and Metabolism, vol. 20, no. 3, pp. 130-138, 2009.

[308] A. Fukuhara, M. Matsuda, M. Nishizawa, K. Segawa, M. Tanaka, K. Kishimoto, Y. Matsuki, M. Murakami, T. Ichisaka, H. Murakami, E. Watanabe, T. Takagi, M. Akiyoshi, T. Ohtsubo, S. Kihara, S. Yamashita, M. Makishima, T. Funahashi, S. Yamanaka, R. Hiramatsu, Y. Matsuzawa, and I. Shimomura, "Visfatin: a protein secreted by visceral fat that Mimics the effects of insulin," Science, vol. 307, no. 5708, pp. 426-430, 2005.

[309] H. Yamawaki, N. Hara, M. Okada, and Y. Hara, "Visfatin causes endothelium-dependent relaxation in isolated blood vessels," Biochemical and Biophysical Research Communications, vol. 383, no. 4, pp. 503-508, 2009.

[310] E. Wanecq, D. Prévot, and C. Carpéné, "Lack of direct insulin-like action of visfatin/Nampt/PBEF1 in human adipocytes," Journal of Physiology and Biochemistry, vol. 65, no. 4, pp. 351-359, 2009.

[311] D. J. Hausenloy, "Drug discovery possibilities from visfatin cardioprotection?" Current Opinion in Pharmacology, vol. 9, no. 2, pp. 202-207, 2009.

[312] E. van der Veer, Z. Nong, C. O’Neil, B. Urquhart, D. Freeman, and J. G. Pickering, "Pre-B-cell colony-enhancing factor regulates NAD+-dependent protein deacetylase activity and promotes vascular smooth muscle cell maturation," Circulation Research, vol. 97, no. 1, pp. 25-34, 2005.

[313] P. Wang, T.-Y. Xu, Y.-F. Guan, D.-F. Su, G.-R. Fan, and C.-Y. Miao, "Perivascular adipose tissue-derived visfatin 
is a vascular smooth muscle cell growth factor: role of nicotinamide mononucleotide," Cardiovascular Research, vol. 81, no. 2, pp. 370-380, 2009.

[314] C. M. Steppan, E. J. Brown, C. M. Wright, S. Bhat, R. R. Banerjee, C. Y. Dai, G. H. Enders, D. G. Silberg, X. Wen, G. D. $\mathrm{Wu}$, and M. A. Lazar, "A family of tissue-specific resistin-like molecules," Proceedings of the National Academy of Sciences of the United States of America, vol. 98, no. 2, pp. 502-506, 2001.

[315] C. L. McTernan, P. G. McTernan, A. L. Harte, P. L. Levick, A. H. Barnett, and S. Kumar, "Resistin, central obesity, and type 2 diabetes," The Lancet, vol. 359, no. 9300, pp. 46-47, 2002.

[316] J. Janke, S. Engeli, K. Gorzelniak, F. C. Luft, and A. M. Sharma, "Resistin gene expression in human adipocytes is not related to insulin resistance," Obesity Research, vol. 10, no. 1, pp. 1-5, 2002.

[317] M. Filková, M. Haluzík, S. Gay, and L. Šenolt, “The role of resistin as a regulator of inflammation: implications for various human pathologies," Clinical Immunology, vol. 133, no. 2, pp. 157-170, 2009.

[318] M. Bokarewa, I. Nagaev, L. Dahlberg, U. Smith, and A. Tarkowski, "Resistin, an adipokine with potent proinflammatory properties," Journal of Immunology, vol. 174, no. 9, pp. 5789-5795, 2005.

[319] S. Verma, S.-H. Li, C.-H. Wang, P. W. M. Fedak, R.-K. Li, R. D. Weisel, and D. A. G. Mickle, "Resistin promotes endothelial cell activation: further evidence of adipokineendothelial interaction," Circulation, vol. 108, no. 6, pp. 736740, 2003.

[320] D. Kawanami, K. Maemura, N. Takeda, T. Harada, T. Nojiri, Y. Imai, I. Manabe, K. Utsunomiya, and R. Nagai, "Direct reciprocal effects of resistin and adiponectin on vascular endothelial cells: a new insight into adipocytokineendothelial cell interactions," Biochemical and Biophysical Research Communications, vol. 314, no. 2, pp. 415-419, 2004.

[321] J. Gómez-Ambrosi and G. Frühbeck, "Evidence for the involvement of resistin in inflammation and cardiovascular disease," Current Diabetes Reviews, vol. 1, no. 3, pp. 227-234, 2005.

[322] H. S. Jung, K.-H. Park, Y. M. Cho, S. S. Chung, H. J. Cho, S. Y. Cho, S. J. Kim, S. Y. Kim, H. K. Lee, and K. S. Park, "Resistin is secreted from macrophages in atheromas and promotes atherosclerosis," Cardiovascular Research, vol. 69, no. 1, pp. 76-85, 2006.

[323] P. Calabro, I. Samudio, J. T. Willerson, and E. T. H. Yeh, "Resistin promotes smooth muscle cell proliferation through activation of extracellular signal-regulated kinase $1 / 2$ and phosphatidylinositol 3-kinase pathways," Circulation, vol. 110, no. 21, pp. 3335-3340, 2004.

[324] C. Ferri, C. Bellini, G. Desideri, R. Baldoncini, G. Properzi, A. Santucci, and G. De Mattia, "Circulating endothelin1 levels in obese patients with the metabolic syndrome," Experimental and Clinical Endocrinology and Diabetes, vol. 105, no. 2, pp. 38-40, 1997.

[325] R. J. Irving, J. P. Noon, G. C. M. Watt, D. J. Webb, and B. R. Walker, "Activation of the endothelin system in insulin resistance," QJM, vol. 94, no. 6, pp. 321-326, 2001.

[326] S. Maeda, S. Jesmin, M. Iemitsu, T. Otsuki, T. Matsuo, K. Ohkawara, Y. Nakata, K. Tanaka, K. Goto, and T. Miyauchi, "Weight loss reduces plasma endothelin-1 concentration in obese men," Experimental Biology and Medicine, vol. 231, no. 6, pp. 1044-1047, 2006.

[327] T. Masaki, “The discovery of endothelins," Cardiovascular Research, vol. 39, no. 3, pp. 530-533, 1998.
[328] I. A. Jagroop, S. S. Daskalopoulou, and D. P. Mikhailidis, "Endothelin-1 and human platelets," Current Vascular Pharmacology, vol. 3, no. 4, pp. 393-399, 2005.

[329] R. Knöfler, T. Urano, J. Malyszko, Y. Takada, and A. Takada, "In vitro effect of endothelin-1 on collagen, and ADPinduced aggregation in human whole blood and platelet rich plasma," Thrombosis Research, vol. 77, no. 1, pp. 69-78, 1995.

[330] T. Scott-Burden, T. J. Resink, A. W.A. Hahn, and P. M. Vanhoutte, "Induction of endothelin secretion by angiotensin II: effects on growth and synthetic activity of vascular smooth muscle cells," Journal of Cardiovascular Pharmacology, vol. 17, supplement 7, pp. S96-S100, 1991.

[331] G. Anfossi, F. Cavalot, P. Massucco, L. Mattiello, E. Mularoni, A. Hahn, and M. Trovati, "Insulin influences immunoreactive endothelin release by human vascular smooth muscle cells," Metabolism, vol. 42, no. 9, pp. 1081-1083, 1993.

[332] C. Haug, R. Voisard, A. Lenich, R. Baur, M. Höher, H. Osterhues, A. Hannekum, U. Vogel, T. Mattfeldt, V. Hombach, and A. Grünert, "Increased endothelin release by cultured human smooth muscle cells from atherosclerotic coronary arteries," Cardiovascular Research, vol. 31, no. 5, pp. 807-813, 1996.

[333] M. E. Ivey, N. Osman, and P. J. Little, "Endothelin-1 signalling in vascular smooth muscle: pathways controlling cellular functions associated with atherosclerosis," Atherosclerosis, vol. 199, no. 2, pp. 237-247, 2008.

[334] I. Komuro, H. Kurihara, T. Sugiyama, F. Takaku, and Y. Yazaki, "Endothelin stimulates c-fos and c-myc expression and proliferation of vascular smooth muscle cells," FEBS Letters, vol. 238, no. 2, pp. 249-252, 1988.

[335] M. Kohno, K. Yokokawa, K. Yasunari, H. Kano, M. Minami, and J. Yoshikawa, "Effect of the endothelin family of peptides on human coronary artery smooth-muscle cell migration," Journal of Cardiovascular Pharmacology, vol. 31, supplement 1, pp. S84-S89, 1998.

[336] N. Ishida, K. Tsujioka, M. Tomoi, K. Saida, and Y. Mitsui, "Differential activities of two distinct endothelin family peptides on ileum and coronary artery," FEBS Letters, vol. 247, no. 2, pp. 337-340, 1989.

[337] A. K. Harris, J. R. Hutchinson, K. Sachidanandam, M. H. Johnson, A. M. Dorrance, D. W. Stepp, S. C. Fagan, and A. Ergul, "Type 2 diabetes causes remodeling of cerebrovasculature via differential regulation of matrix metalloproteinases and collagen synthesis: role of endothelin-1," Diabetes, vol. 54, no. 9, pp. 2638-2644, 2005.

[338] S. Naito, S. Shimizu, S. Maeda, J. Wang, R. Paul, and J. A. Fagin, "Ets- 1 is an early response gene activated by ET- 1 and PDGF-BB in vascular smooth muscle cells," American Journal of Physiology, vol. 274, no. 2, pp. C472-C480, 1998.

[339] J. Rodriguez-Vita, M. Ruiz-Ortega, M. Rupérez, V. Esteban, E. Sanchez-López, J. J. Plaza, and J. Egido, "Endothelin-1, via ETA receptor and independently of transforming growth factor- $\beta$, increases the connective tissue growth factor in vascular smooth muscle cells," Circulation Research, vol. 97, no. 2, pp. 125-134, 2005.

[340] K. P. Karalis, P. Giannogonas, E. Kodela, Y. Koutmani, M. Zoumakis, and T. Teli, "Mechanisms of obesity and related pathology: linking immune responses to metabolic stress," FEBS Journal, vol. 276, no. 20, pp. 5747-5754, 2009.

[341] V. Bourlier and A. Bouloumie, "Role of macrophage tissue infiltration in obesity and insulin resistance," Diabetes and Metabolism, vol. 35, no. 4, pp. 251-260, 2009.

[342] E. Ingelsson, M. G. Larson, X. Yin, T. J. Wang, J. B. Meigs, I. Lipinska, E. J. Benjamin, J. F. Keaney Jr., and 
R. S. Vasan, "Circulating ghrelin, leptin, and soluble leptin receptor concentrations and cardiometabolic risk factors in a community-based sample," Journal of Clinical Endocrinology and Metabolism, vol. 93, no. 8, pp. 3149-3157, 2008.

[343] M. K. Öhman, A. P. Wright, K. J. Wickenheiser, W. Luo, and D. T. Eitzman, "Visceral adipose tissue and atherosclerosis," Current Vascular Pharmacology, vol. 7, no. 2, pp. 169-179, 2009. 


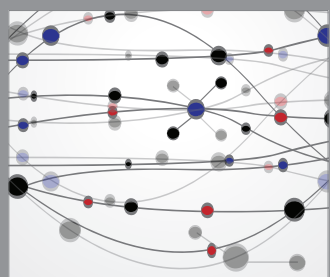

The Scientific World Journal
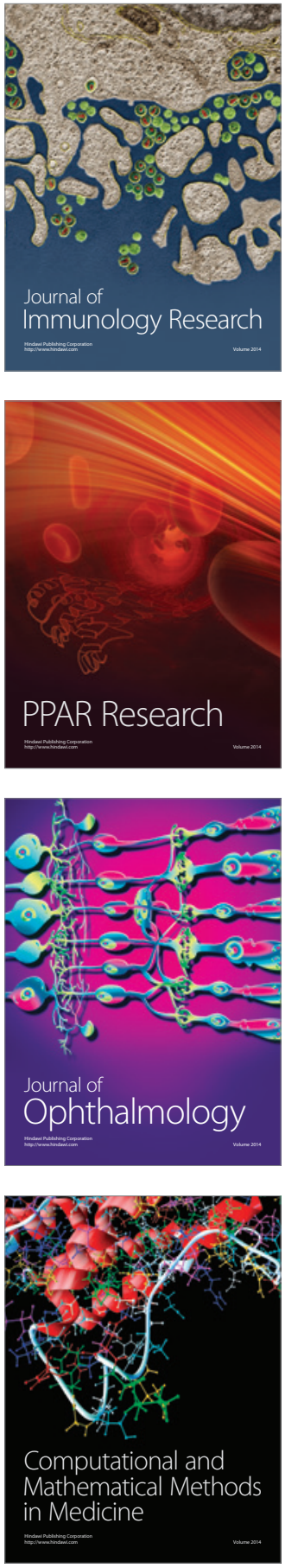

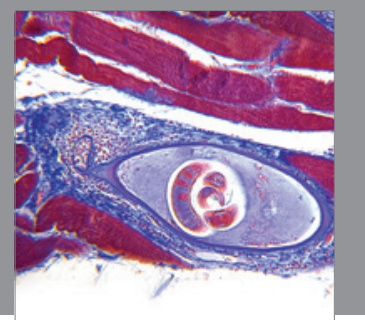

Gastroenterology

Research and Practice
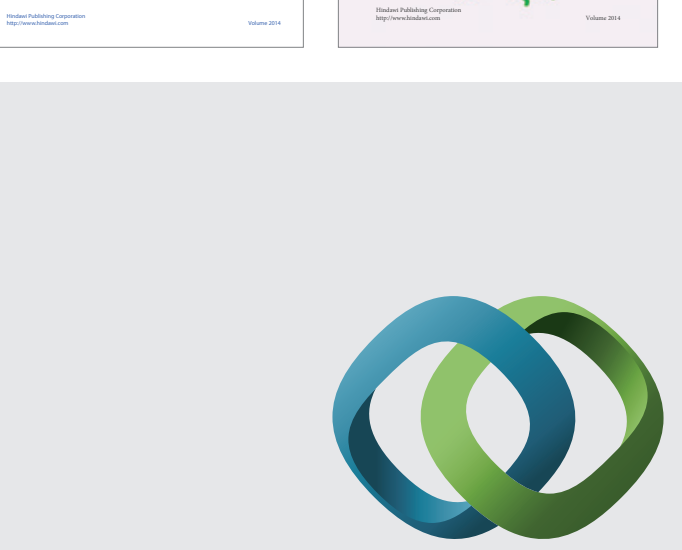

\section{Hindawi}

Submit your manuscripts at

http://www.hindawi.com
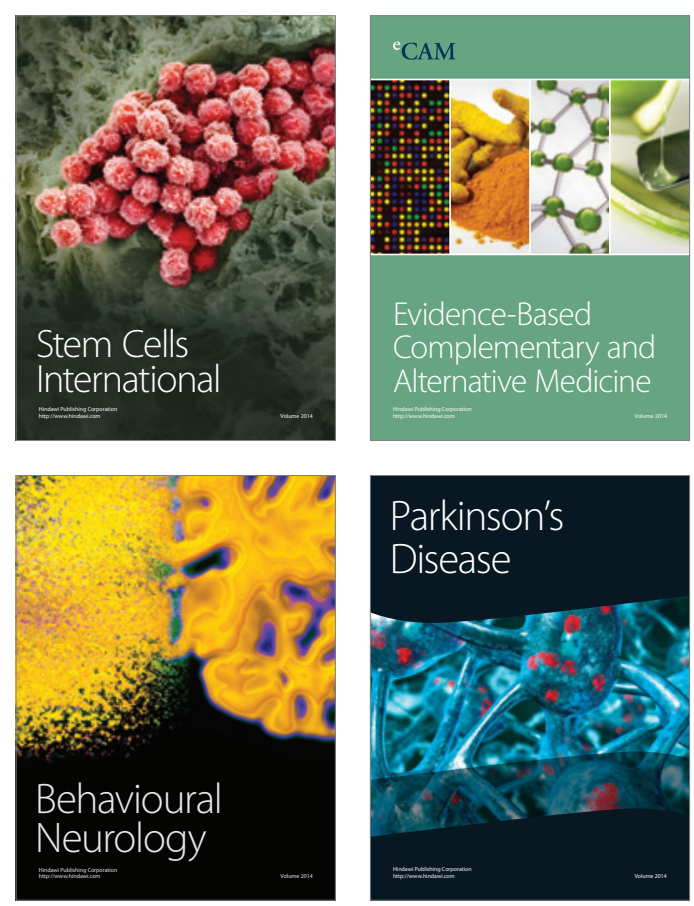

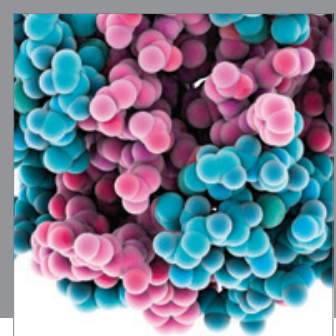

Journal of
Diabetes Research

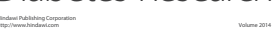

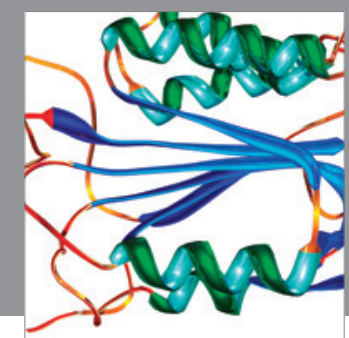

Disease Markers
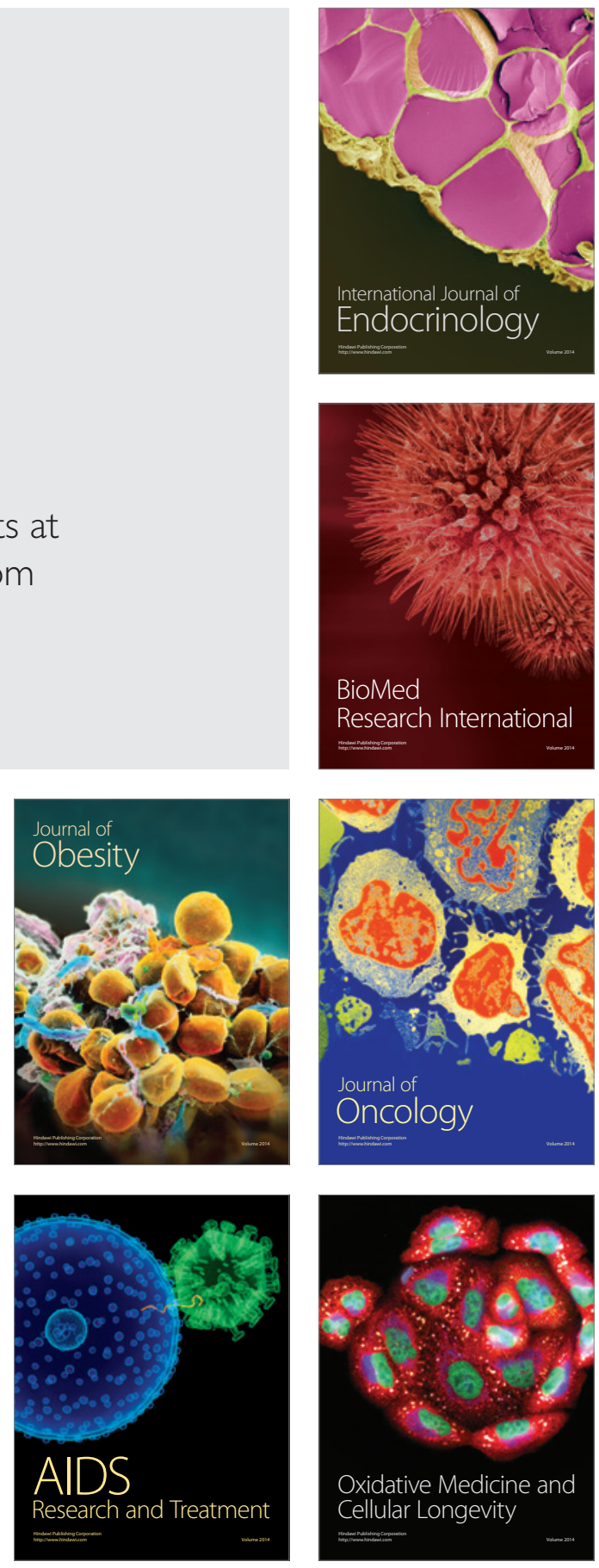